\title{
Managerial Legacies, Entrenchment and Strategic Inertia*
}

\author{
Catherine Casamatta \\ CRG, University of Toulouse I
}

\author{
Alexander Guembel \\ Saïd Business School \\ and \\ Lincoln College \\ University of Oxford
}

January 10, 2007

\footnotetext{
${ }^{*}$ We would like to thank Bruno Biais, Roberta Dessì, Andrea Eisfeldt, Guido Friebel, Denis Gromb, Eugene Kandel, Thomas Mariotti, Colin Mayer, Meg Meyer, Jean Charles Rochet, Elu von Thadden, Lucy White and seminar participants at Nuffield College, Mannheim University, Saïd Business School, the 4th Corporate Finance workshop at the LSE, the EFMA 2005, ESSFM Gerzensee 2005, the 10th Anniversary Finance Meeting of CEMAF/ISCTE and the AFA 2006 for helpful comments. Guembel would like to thank the IDEI, where part of this research was carried out, for their kind hospitality and gratefully acknowledges funding received by the Michael Zilkha Trust at Lincoln College. All remaining errors are ours.

Correspondence address: Alexander Guembel, Lincoln College, Oxford, OX1 3DR, UK, Tel.: +44 1865288914 , e-mail: alexander.guembel@sbs.ox.ac.uk
} 


\title{
Managerial Legacies, Entrenchment and Strategic Inertia
}

\begin{abstract}
This paper investigates a firm's decision to retain or fire a poorly performing CEO when the CEO's choice of strategy has long-term cash flow implications beyond the CEO's tenure (he leaves behind a legacy). Replacing a CEO becomes expensive and entrenchment emerges, because the firm's future performance can only partially be attributed to a newly employed manager. This makes it more expensive to provide incentives to a new manager. Moreover, when the firm chooses to change its strategy it will optimally do so with a different manager, because the incumbent has a vested interest in seeing the new strategy fail: Failure improves the incumbent's reputation because it is regarded as a vindication of his original choice. Changing strategy, however, is costly, because of the high explicit wages that a new manager needs to be paid. Firms therefore exhibit inertia in their adoption of new strategies. We thus endogenise the link between CEO turnover and strategy changes. We derive empirical implications regarding firm's policies to re-set the strike price of executive stock options, managerial replacement decisions, and capital reallocation.
\end{abstract}

Keywords: Reputational concerns, executive stock options, entrenchment, strategic inertia, managerial turnover.

JEL classification numbers: D82, G30, J33

\section{Introduction}

A company's CEO typically takes actions that affect the firm's future performance beyond his own tenure. The CEO leaves behind a legacy. How can a firm incentivize a new CEO who inherits the legacy? How does a legacy affect the firm's decision to dismiss a poorly performing CEO and to adopt new strategies? And what is the nature of the relationship between a CEO and the strategy he stands for? Even though these questions are at the core of company's concerns in the face of poor performance, existing theory provides little guidance regarding the economic mechanisms that link CEOs to strategies or that link successive CEOs intertemporally. This paper is aimed at addressing these questions.

The starting point of this paper is the observation that there is an intertemporal link between a new CEO's incentives and the actions taken by his predecessor. The fact that such a link exists is probably more recognized in the accounting literature than in economics. Pourciau (1993) for example provides evidence that the successor of a CEO who has left the firm for non-routine reasons, 
tends to depress accounting earnings during their first year in office. Pourciau interprets this as an attempt 'to take a bath while still being able to blame the predecessor.' In addition, there is rich anecdotal evidence that illustrates the prevalence of the blame game in which CEO successors often engage, with the corresponding challenge for outsiders to attribute responsibility fairly. For example, when Mike Parton, former CEO of Marconi, was asked "How much blame do you accept for Marconi's [...] troubles?" he replied that "You can't be part of management and just wash your hands of it. However, I was not a board member when the key strategic decisions were made, and it's difficult to say what my view might have been had I been on the board at the time." 1

This paper formalizes the intertemporal link between the performance of two generations of CEOs and thereby introduces the notion of a managerial legacy. When a CEO works for a firm he may initiate a long-term strategy that affects the distribution of the firm's cash flows for several periods into the future. For example, decisions that involve large capital expenditures or that establish a firm's reputation in a particular market segment typically have long lasting impact. Because of this, such long-term strategic decisions may affect the incumbent CEO's future incentives to implement a given strategy as well as the incentives of a potential successor who inherits the incumbent CEO's legacy. By the same token, if the firm can adopt a new strategy, its success or failure may throw light on the quality of the initial strategic decision made by the CEO. This gives the incumbent CEO a vested interest in seeing his initial strategy succeed that a new manager does not have in the same way. Conversely, an incumbent CEO who has to change strategy may have a vested interest in seeing that new strategy fail so as to vindicate his original choice. As a result contract design, employment decisions and strategy choices are intrinsically linked. The aim of this paper is to explore these dynamic links when managers can create legacies in the firms they manage.

We consider a set-up in which a firm manager can be incentivized both explicitly and implicitly through reputational concerns. The manager needs to take a long-term strategic decision the quality of which depends on his intrinsic and unknown ability. After a strategy has been chosen it needs to be implemented, which requires managerial effort over two periods. Cash flows are also generated over two periods and depend both on the initial choice of strategy and on the implementation effort. The firm can dismiss the incumbent manager after poor performance and hire a new manager to continue the project's implementation. We assume that a new manager is equally well suited to implement the project.

We first determine the optimal wage contracts and employment policy for shareholders. We show that in the presence of reputational concerns by managers, the threat of firing after bad performance is time inconsistent, i.e., the incumbent manager is entrenched. The reason is that it is cheaper to employ an incumbent manager after he performed badly than to hire a new manager, because the new manager knows that his reputation is less sensitive to performance than that of the incumbent. As a result, higher explicit incentives for the new manager have to replace

\footnotetext{
${ }^{1}$ Institutional Investor, April 2004.
} 
the implicit incentives of the incumbent, which is costly to the firm. From an ex ante point of view, entrenchment can be costly, though. We characterize under which conditions entrenchment is detrimental to shareholders.

Second, we explore how the presence of a legacy affects the joint decision to change manager and strategy. We therefore allow for the case where the firm can change its strategy at an interim date. We show that in such a situation, the firm will always change the manager if it changes its strategy. This is because the manager's reputation is linked to his original decision, which gives him an incentive to 'sabotage' the new strategy. Hence, we predict that there is a close association between changes in a firm's strategy and managerial turnover. A direct implication of this is that firms will exhibit strategic inertia. In the presence of reputational concerns, the firm faces a cost when it changes strategy: it forgoes the advantage of employing a manager who is incentivized strongly by the desire to prove that his original strategy choice was correct. The firm may therefore refrain from changing strategy (and manager) even when it knows that an alternative strategy is more likely to be profitable.

To illustrate the ideas developed in this paper, consider the example of the recent changes at DaimlerChrysler. Former CEO Jurgen Schrempp was replaced by Dieter Zetsche in January, 2006, after 10 years at the head of the company. Schrempp's vision had been to create a 'Welt AG' (World Inc), i.e. the world's leading transportation company. To do this, he merged Daimler and Chrysler in 1998, and took important stakes in Asian carmakers Mitsubishi and Hyundai in 2000. Despite subsequent years of poor performance, and against general opinion, Schrempp was not dismissed. Quite unexpectedly, a few months after renewing Schrempp's mandate in early 2005, the board of directors decided to dismiss him, to promote Dieter Zetsche, and to abandon the firm's worldwide strategy in favor of a refocus on the firm's core competencies. Business analysts' comments were: "The back-to-basics move, which aims to streamline management and cut costs by a net $\$ 1$ billion a year is a dramatic reversal of the imperial management culture and highflying ambitions of predecessor Jurgen Schrempp." 2 This paper offers an explanation for why Schrempp and his 'World Inc' strategy were maintained so long in spite of poor performance, and why Schrempp's replacement coincided with the Board of Directors' decision to change strategy.

In a nutshell, we argue that Schrempp was retained because his incentives to make the existing strategy work were considerably higher than those of a potential successor. By the same token, once it was decided that this strategy should be abandoned, a new CEO was required to implement the new strategy. It is hard to see how Schrempp could have had a serious interest in dismantling his own strategy and pushing forward a new one. Of course, we cannot rule out the possibility that Zetsche was considered more able than Schrempp at implementing the new strategy. In fact, it is probably part of the reason why he was chosen among the successor candidates. ${ }^{3}$ Still, this argument alone cannot explain why it took so long for the board to dismiss Schrempp. There was

\footnotetext{
${ }^{2}$ BusinessWeek online, january 25, 2006.

${ }^{3}$ Indeed, Zetsche acquired a good reputation at implementing cost-cutting strategies by successfully restoring profits when he was director at Chrysler.
} 
general agreement on the fact that Schrempp showed exceptional longevity considering the financial troubles endured by DaimlerChrysler throughout his mandate.

Last, we address the question of the implementation of the optimal wage contract, and show that when the incumbent manager is retained, the second period compensation contract can be interpreted as a stock option scheme with reset exercise prices in response to poor performance. Our paper thus offers a rationale for the observation that CEOs are often retained and executive stock options are reset to a lower strike price in response to poor performance (Brenner, Sundaran and Yermack (2000), Chance, Kumar and Todd (2000)). ${ }^{4}$ We identify two distinct determinants of the second period compensation contract and thus two distinct reasons for repricing. Firstly, repricing may occur in order to refresh the manager's second period incentives after his existing stock options have become of little value. ${ }^{5}$ Second, repricing may occur to retain the incumbent manager. This happens when his reputational concerns are very high. At that point the manager has a strong incentive to resign, and free-ride on the future manager's effort in order to rehabilitate his reputation. Our paper thus can account for both rationales for stock option repricing put forward by practitioners.

More generally, our analysis allows to derive predictions regarding executive compensation packages, employment policies, and strategic choices, and directly speaks to some empirical findings in the literature. First, we show that managerial retention and executive stock-option repricing after bad performance are optimal when reputational concerns are strong, and when firms have to make long-term strategic choices. We would therefore expect entrenchment and stock-option repricing to be more prevalent at the stage of a firm's life when a long-term strategic choice continues to impact on the firm's future performance. This prediction is borne out by the empirical evidence in Carter and Lynch (2001) and Chidambaran and Prabhala (2003) who find that repricing is more prevalent in younger firms and firms that are more concentrated in the technology sector. Both attributes fit our description of firms where long-term strategic choices are particularly important. Our analysis specifies that one should observe more strategic continuity when managers are retained, and stock options are repriced.

Second, our results predict both a reluctance to change strategy after bad performance, and a close association between managerial replacement and major changes in the firm's strategy. Taken together, these two predictions can help to understand why CEO turnover is significantly correlated with strategic change, while poor performance alone is not (see for instance Romanelli and Tushman (1994), Gordon, Stewart, Sweo and Luker (2000) and Dass (2006)).

Finally, we identify reputational concerns as a possible contractual friction that prevents firms from reallocating assets to their more productive use. Our analysis can shed light on the empirical

\footnotetext{
${ }^{4}$ Alternative explanations for the observed 'leniency' of board towards CEOs rely on the idea that top executives wield power in setting their own wage (Bebchuk and Fried (2003), Bertrand and Mullainathan (1999, 2001)). We show here that these seemingly sub-optimal compensation packages are compatible with shareholder value maximization.

${ }^{5}$ Acharya, John and Sundaram (2000) also highlight this point. They do not, however, consider the possibility of replacing the manager after poor performance. Our paper explicitly addresses this question and integrates the analysis of optimal incentive contracts and employment policy.
} 
findings of Eisfeldt and Rampini (2005) who document that the benefits of capital reallocation are underexploited during recessions. To the extent that managerial expertise is more needed, when profits are low and investment opportunities are scarce, our model provides an explanation for the observed lack of capital reallocation.

\section{Relation to the literature}

Our paper relates to a number of contributions in the theory of dynamic incentives, based on moral hazard issues (see Holmstrom (1979) and Rogerson (1985) for the analysis of, respectively, static and dynamic models of moral hazard). ${ }^{6}$ The role of implicit incentives through reputational concerns was pioneered by Holmstrom (1982) and extended to allow for explicit incentives by Gibbons and Murphy (1992). The literature building on this mainly focuses on incentive distortions that arise out of reputational concerns (e.g., Holmstrom and Ricart-i-Costa (1986), Jeon (1998), Milbourn, Shockley and Thakor (2001)). We depart from this literature by stressing the fact that managerial talent can influence the choice of long-term projects. Therefore, each period cash flow provides information on the quality of the original project choice, and affects differently the reputation of the manager who made the initial choice, compared to the reputation of a later-coming manager. In most of the literature on career concerns, managerial ability affects only the current period cash flows, and any manager's reputation is updated regardless of his history with the firm. ${ }^{7}$ This setting allows us to investigate the relationship between career concerns, dismissal and explicit incentives. In the above quoted literature, dismissal does not typically arise as an issue, because managers are in perfect competition at each date, driving wage down to the point where the firm is indifferent between continuation with the same or another manager. In our setting this is no longer true, because managers take an action that has long lasting impact. While the standard result of career concerns stresses the fact that old managers have less career concerns than young ones and should be given more explicit incentives, our model shows that managerial tenure within a firm can increase reputational concerns, and reduce the use of explicit incentives.

The role of a termination threat in managerial incentives has received a lot of attention in the literature on debt as a commitment device (e.g., Diamond (1984), Gale and Hellwig (1985), Bolton and Scharfstein (1990), Aghion and Bolton (1992), Dewatripont and Tirole (1994) and others). In line with this literature, our analysis shows that if the termination threat can be desirable from an ex ante point of view, it is ex post inefficient, and can be subject to renegotiation. ${ }^{8}$ However, we depart from this literature along several dimensions. First, the cost of termination is not exogenous in our model: it is reflected in the higher incentive cost of hiring a new manager with lower

\footnotetext{
${ }^{6}$ See Prendergast (1999) for a review on incentives in firms, and Abowd and Kaplan (1999) and Murphy (1999) for reviews on incentive compensations for executives.

${ }^{7}$ Reputation updating can be asymetric across managers though, if managers are given more or less power to take decisions, as pointed out by Ortega (2003), or if intrafirm communication is limited as in Friebel and Raith (2004).

${ }^{8}$ In that sense, our analysis is also related to the theoretical literature on soft budget constraint, initiated by Dewatripont and Maskin (1995).
} 
reputational concerns. As a consequence, committing to fire the manager ex ante is not always optimal, while in those models, it is always ex ante optimal to threaten to liquidate. Second, these papers assume that a manager is perfectly entrenched and the only way to provide a termination threat is to liquidate the firm, i.e., it is impossible to fire a manager, hire a new one and continue the firm. ${ }^{9}$ This assumption is typically justified with reference to asset (or strategy) specific skills that render a manager indispensable (e.g., Shleifer and Vishny (1989)). While we believe that such specific skills do play a role in practice, we also believe that the relationship between a manager and a firm's chosen strategy goes beyond specific skills. We therefore make the (extreme) assumption that managers have no inherent productivity advantages in implementing a given strategy, and can be replaced by equally efficient managers. Entrenchment then arises endogenously from the incentive implications of managerial legacies.

Almazan and Suarez (2003) show that managerial entrenchment may arise as an optimal arrangement when the board of directors is weak. This is because entrenchment reduces the amount of explicit incentives necessary to pay a manager. In their paper severance payments emerge as a way to provide optimal ex ante incentives for effort choice. ${ }^{10}$ Almazan and Suarez (2003) use quite a different notion of entrenchment from ours. Entrenchment for them means that a manager is retained even though it is ex post inefficient, because it is ex ante optimal to do so. We use entrenchment to describe the ex ante inefficient retention of a manager due to the ex post optimality of retaining him. ${ }^{11}$

There is little literature that explicitly addresses the dynamics of strategy change. Dow and Raposo (2005) argue that firms' strategic choices are suboptimal in that managers have a preference for projects that are difficult to implement. Their model, however, focuses on a static set-up where a manager has considerable lee-way in the initial strategy formulation, but once a strategy has been chosen the issue of change does not arise. Our paper is quite different in that we explore the dynamics of wage, employment and strategy change. Boot (1992) and Prendergast and Stole (1996) consider a CEO's incentive to respond to private information about the quality of the firm's strategy (or investment project). In both papers changing strategy may reflect badly on the CEO's ability, which can lead to underreaction to private information. Prendergast and Stole (1996) show that CEOs with long (short) tenure may under- (over-) react to private information. Like them, we identify tenure as an important variable determining willingness to change strategy. However, in contrast to both the above papers, we do not assume that CEOs have private information about the best project. We therefore find that firms may exhibit strategic inertia not only from the perspective of the manager's private information, but also conditional on publicly available information. This

\footnotetext{
${ }^{9}$ See, however, Zwiebel (1996), Fluck (1998) and Berkovitch, Israel and Spiegel (2000) who assume that managers can be replaced at a cost and derive capital structure implications. See also Spear and Wang (2005) who extend the standard dynamic moral hazard framework to the case where the agent can be replaced.

${ }^{10}$ Severance payments also appear to be an optimal response to managerial incentives in Eisfeldt and Rampini (2004). In that paper, severance payments help eliciting information on the projet's productivity by compensating managers for loss of control.

${ }^{11}$ In that sense, our paper is closer to Crémer (1995) who shows that firms may not be able ex post to fire poorly performing managers if they can attribute it to bad luck, although it would be ex ante optimal to do it.
} 
observation appears to be consistent with the anecdotal evidence described above, whereby firms fail to adopt a new strategy in spite of a widespread understanding that the current strategy is not optimal.

The organization of the paper is the following. Section III presents the basic model structure. In Section IV, we solve for the optimal wage contracts and the firm's firing policy when the CEO chooses a strategy that cannot subsequently be changed. Section V explores wage contracts, and managerial turnover when the firm can switch strategies at the interim date. Section VI discusses the implementation of wage contracts and empirical implications, while Section VII discusses some model extensions. The Appendix contains proofs.

\section{The model}

There are three dates $t=0,1,2$. A firm can undertake a project at the initial date $t=0$, which yields an uncertain payoff at the two subsequent dates. The project choice can be thought of as a long-term strategic decision by the firm, which will affect the firm's cash flows two periods into the future. The firm hires a manager whose task it is to make this strategic choice and to implement it subsequently. Assume that the manager's choice of strategy $S$ can be either good $(S=G)$ or bad $(S=B)$. Once a strategy has been chosen it cannot be changed for two periods. Later on we will also consider the case where the firm can adopt another strategy at the interim date.

There are two types of managers, $m \in\{L, H\}$. High type managers $(m=H)$ always pick the good strategy, whereas low types always pick the bad strategy. ${ }^{12}$ The ex ante probability of a manager being a high type is $q_{0} \geq \frac{1}{2}$. The manager's type is not known to either the manager or the firm, and both have the same beliefs about the manager's type. Moreover, we assume that neither can observe directly the quality of the chosen strategy.

Once a strategy has been chosen, its likelihood of success depends on the effort that a manager puts into its implementation over the next two periods. The firm then generates payoffs at $t=1,2$. Denote by $e_{1} \in\left\{\underline{e}_{1}, \bar{e}_{1}\right\}$ the effort choice, that affects payoffs at $t=1$. Similarly, $e_{2} \in\left\{\underline{e}_{2}, \bar{e}_{2}\right\}$ is the effort chosen after the first-period payoffs, affecting payoffs at the final date $t=2$. Exerting the high effort level $\bar{e}_{t}>\underline{e}_{t}$ accrues a cost $c$ to the manager. Define the increase in effort levels by $\Delta e_{t} \equiv \bar{e}_{t}-\underline{e}_{t}$. The choice of effort affects payoffs in the following way. The payoff is always low $\left(R_{l}\right)$ when the manager has chosen the bad strategy $S=B$, i.e., any effort by the manager in either period is wasted in that case. When he has chosen the good strategy $S=G$ the firm generates a high payoff $R_{t}=R_{h}$ at $t=1$ with probability $e_{1}$ and the low payoff $R_{l}$ with probability $1-e_{1}$. Date $t=2$ payoffs are affected by effort $e_{2}$ in the same way. Figure 1 summarizes the structure of the model.

Suppose first that effort is observable, that is, that there is no moral hazard. To make things

\footnotetext{
${ }^{12}$ Note that our results go through if we assume that a bad manager can sometimes choose a good strategy. What matters for our results is that the project's choice cannot be perfectly inferred from the realization of the profits at each period.
} 


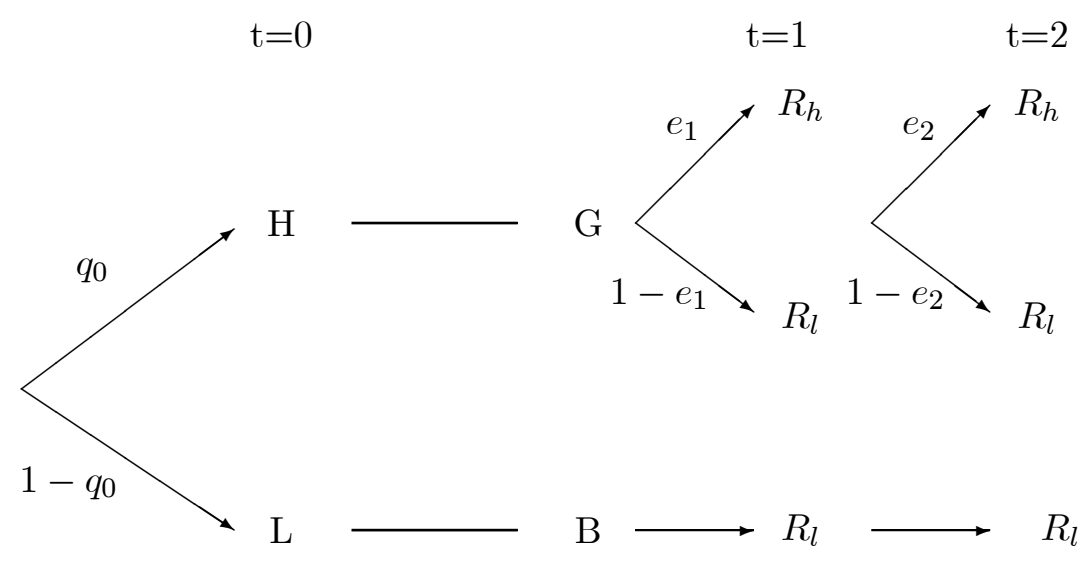

Figure 1: Timing and payoffs under symmetric information.

interesting, we assume that in that case the firm maximizes its profit by inducing effort at any stage of the game. This implies the following conditions. First, the firm wants to hire a manager and to induce effort at $t=2$, whatever the level of profit realized at the end of the first period. This is ensured by the condition:

$$
p^{i}\left(\bar{e}_{2} R_{h}+\left(1-\bar{e}_{2}\right) R_{l}\right)+\left(1-p^{i}\right) R_{l}-c \geq p^{i}\left(\underline{e}_{2} R_{h}+\left(1-\underline{e}_{2}\right) R_{l}\right)+\left(1-p^{i}\right) R_{l},
$$

where $p^{i} \equiv \operatorname{prob}\left(S=G \mid R_{1}=R_{i}\right)$ and $i \in\{l, h\}$.

After manipulations, the above equation boils down to:

$$
R_{h}-R_{l} \geq \frac{c}{p^{i} \Delta e_{2}}
$$

Second, the firm wants to hire a manager and induce him to exert effort at $t=1$, given that effort will be induced at $t=2$. This is ensured by the condition:

$$
\begin{gathered}
q_{0}\left[\bar{e}_{1} R_{h}+\left(1-\bar{e}_{1}\right) R_{l}+\bar{e}_{2} R_{h}+\left(1-\bar{e}_{2}\right) R_{l}-c\right]+\left(1-q_{0}\right)\left[R_{l}+R_{l}-c\right]-c \geq \\
\left.q_{0}\left[\underline{e}_{1} R_{h}+\bar{e}_{2} R_{h}+\left(1-\bar{e}_{2}\right) R_{l}\right)-c+\left(1-\underline{e}_{1}\right) R_{l}\right]+\left(1-q_{0}\right)\left[R_{l}+R_{l}-c\right],
\end{gathered}
$$

which simplifies to:

$$
R_{h}-R_{l} \geq \frac{c}{q_{0} \Delta e_{1}}
$$

The firm hires a manager at $t=0$ with reputation $q_{0}$ and offers a wage contract that specifies compensation payments contingent on the date 1 and 2 payoffs. Denote by $w^{i, j}$ the wage payment at date $t=2$ contingent on both performance observations $R_{i}, R_{j}$ at dates 1 and 2 respectively, where $i, j \in\{l, h\}$. The firm can choose to fire the manager at $t=1$ and hire a new manager from a pool of indistinguishable managers of reputation $q_{0}$. The effort level $e_{t}, t=1,2$ is chosen by the manager who is employed by the firm at date $t-1$. Note that the firm can offer different 
second period wage contracts to a new or the incumbent manager. Similarly, we denote date 1 wage payments by $w^{i}$. Finally, let $p^{i, j} \equiv \operatorname{prob}\left(S=G \mid R_{1}=R_{i}, R_{2}=R_{j}\right)$.

Managers are risk neutral and have limited liability. We also assume that they care about their reputation when they stop working for the firm (or when the project stops). Denote by $f(q)$ the value that a manager derives from having reputation $q$. We assume that $f(q)$ is i) increasing in $q$, 13 and ii) such that the manager would prefer to accept to be employed by the firm at the initial date instead of not being employed. Intuitively, when the firm performs well, outside firms will be more eager to hire well-performing managers, and be willing to pay them higher wages. This assumption is also consistent with recent empirical evidence by Fee and Hadlock (2003) who show that managers who are promoted to CEO positions at new firms come from firms with better than average past stock price performance.

Denote by $q^{i, j}$ the date 2 reputation ${ }^{14}$ of the manager conditional on the performance observations $R_{i}, R_{j}$ at date 1 and 2 respectively, where $i, j \in\{l, h\}$. We can similarly define the date 1 reputation by $q^{i}$. Moreover, we assume that the manager remains unemployed for one period if he is fired at date 1 . After that, his reputation is updated on the basis of the firm's cash flows. The manager's reputation therefore continues to evolve even when he no longer works for the firm.

Given the structure of the model reputation evolves in a very simple way: if the firm generates high cash flows $R_{h}$ at either date, it becomes clear that the manager must have picked the correct strategy $S=G$. His reputation then jumps to $q=1$, because only high type managers are capable of choosing a good strategy. This yields the following reputation updates: $q^{h}=q^{h, l}=q^{h, h}=q^{l, h}=1$. The manager enjoys then a reputation benefit $f(1)$. The only other remaining reputation updates are then $q^{l}<1$ after bad performance at $t=1$, and $q^{l, l}<q^{l}$ after two consecutive bad performances. At the end of period 2, we can denote the difference in the value of the reputation between $q=1$ and $q^{l, l}$ by $\Delta f \equiv f(1)-f\left(q^{l, l}\right)$.

Last, in the remainder of the paper, we make the assumption that effort is not observable, i.e. that there is moral hazard.

\section{Optimal wages and firing policy}

We now analyze the wage contracts and the optimal retention policy of the firm. Throughout the paper we restrict attention to long-term contracts that are renegotiation proof. In other words, we allow the firm and the manager to renegotiate the employment contract if it is mutually profitable to

\footnotetext{
${ }^{13}$ One can think of $f(q)$ being determined by an explicit calculation of the net present value of future wage payments when the agent has current reputation $q$. For the sake of tractability we will not endogenize $f(q)$, but simply assume that the higher the manager's reputation, the higher the future expected wage (see Dewatripont, Jewitt and Tirole (1999) for a comprehensive analysis of career concerns models).

${ }^{14}$ In our model, reputation is the probability of the manager being of a good type. Because we assume a perfect match between types and strategy choices, the reputation $q^{i, j}$ is equal to the probability of having picked the correct strategy $p^{i, j}$. Both may differ in a more general setting. To interpret more accurately the economic effects at stake, we maintain distinct notations for the two variables.
} 
do so. ${ }^{15}$ In our case this means that the firm cannot write a contract that commits it to a particular employment policy. And the firm cannot force the manager to work for it if this would violate his participation constraint at the interim date. Hence, we do not allow employment contracts that i) are ex post detrimental to shareholders, and ii) would deny the manager the right to quit the job if he wishes to do so. Of course, since managers will anticipate this, it will modify their ex ante incentives to work.

\section{A. Optimal second period wages}

Let us first consider the firm's employment policy and wage payments at the interim date. The wage contract and the decision to retain or fire the manager at the interim date 1 are determined so as to maximize shareholder wealth, subject to the manager's incentive compatibility and participation constraints. The following proposition gives the optimal wage contracts that maximize shareholders' wealth and satisfy both sets of constraints, depending on whether the incumbent manager is retained or fired and depending on whether date 1 cash flows were high or low. ${ }^{16}$

Proposition 1 Suppose the firm earns $R_{h}$ at date 1 . Then the optimal date 2 wage contract is the same regardless of whether the manager is retained or fired at date 1. The optimal wage contract is given by

$$
\begin{aligned}
w^{h, h} & =\frac{c}{\Delta e_{2}}, \\
w^{h, l} & =0 .
\end{aligned}
$$

Suppose the firm earns $R_{l}$ at date 1 . The optimal date 2 wage contract if a new manager is hired is given by

$$
\begin{aligned}
w_{\text {new }}^{l, h} & =\frac{c}{p^{l} \Delta e_{2}} \\
w_{\text {new }}^{l, l} & =0
\end{aligned}
$$

and if the original manager is retained it is given by

$$
\begin{aligned}
& w_{\text {old }}^{l, h}=\max \left\{\frac{c}{p^{l} \Delta e_{2}}-\Delta f ; \frac{c}{p^{l} \bar{e}_{2}}\right\}, \\
& w_{\text {old }}^{l, l}=0 .
\end{aligned}
$$

The wage payment $w^{h, h}$ from performing well in the second period, after having performed well in the first period is independent of reputational concerns. The reason is straightforward: when

\footnotetext{
${ }^{15}$ This assumption appears to be consistent with the empirical evidence provided by Chen (2004). He finds that firms that 'commit' not to reprice options, issue an abnormally large amount of new stock options. This suggests that firms do reward managers after poor performance, even when they -try to- commit not do so.

${ }^{16}$ We assume as before that shareholders want to induce effort at the second period, whatever the first period cash-flows, and we provide below a sufficient condition for this.
} 
the manager has performed well once, it is known that he chose the good strategy initially and therefore he cannot improve his reputation further by performing well again. Therefore the same wage is given to an incumbent or a new manager. ${ }^{17}$

When the incumbent manager is fired after poor interim performance and a new manager is hired, he receives a wage payment only if he performs well at the subsequent date. In this way the manager is given stronger incentives to exert effort. The total reward required is $\frac{c}{p^{l} \Delta e_{2}}$, which is exactly the payment that satisfies the new manager's incentive compatibility constraint. His participation constraint is always satisfied at this wage level.

When the incumbent manager is retained, there are two possible values of the wage payment when he performs well, depending on whether the incentive compatibility or the participation constraint is binding. The incentive compatibility constraint requires a 'bonus' payment $w_{\text {old }}^{l, h}=$ $\frac{c}{p^{l} \Delta e_{2}}-\Delta f$. This is similar to the wage payment given to a new manager, except that now not all incentives have to be provided explicitly. The incumbent manager is concerned about his reputation and therefore some of his incentives are provided implicitly. This reduces the necessary explicit wage payment by an amount $\Delta f$ corresponding to his reputational concern (see equation (6)).

The difference arises because only the incumbent, but not the new manager is driven by reputational concerns: The latter cannot be held responsible for the initial strategic choice and therefore a failure to implement the strategy successfully, does not allow the market to update its belief over the new manager's ability to take good strategic decisions. Therefore reputational concerns provide incentives to the incumbent manager, but not the new manager.

This result differs from standard results in the literature (e.g., Holmstrom's (1982), Gibbons and Murphy (1992)), where a manager's compensation contract is determined only on the basis of his current reputation and his remaining reputational concerns. We show that managers receive very different compensation contracts solely on the basis of whether or not they have worked in the firm before, and thereby had an opportunity to affect the distribution of the firm's cash flows beyond the time horizon of their own tenure.

When the reputational concerns become very strong, the incumbent manager's incentive compatibility constraint can be satisfied without any explicit wage payment. The manager is willing to exert effort merely in order to improve his reputation, and does not need a monetary gain. But, this raises the possibility for the incumbent manager to leave the firm and free ride on the effort exerted by a new manager: he would then obtain the reputation benefit without incurring the effort cost. If the firm wishes to retain the incumbent manager it has to give him a positive wage even though his incentive compatibility constraint is slack. This wage is determined by the binding participation constraint of the manager, and is equal to $\frac{c}{p^{l} \bar{e}_{2}}$.

\footnotetext{
${ }^{17}$ Under more general information structures the incumbent manager may well continue to have reputational concerns after good performance, which will simply provide an additional reason for retaining the incumbent manager after good performance.
} 
Corollary 1 If

$$
\Delta f>\frac{\underline{e}_{2}}{\bar{e}_{2}} \frac{c}{p^{l} \Delta e_{2}}
$$

then the second period wage contract is determined so as to ensure that the incumbent manager can be retained. Otherwise the second period wage contract is determined so as to render the high effort level incentive compatible.

Our model captures two realistic features of dynamic wage contracting in a simple set-up. Wage contracts have to satisfy an incentive compatibility constraint, which is the usual constraint that much of the theoretical literature on agency problems has focused on. ${ }^{18}$ At the same time wage contracts have to satisfy a non-trivial participation constraint in order to deter the manager from leaving the firm with a view to free-riding on effort exerted by another manager in the future. This effect is not captured in previous models of CEO compensation, even though managerial retention is one of the main concerns stated for repricing by practitioners. In most models of CEO compensation it is assumed that managers take actions whose impact expires after one period. ${ }^{19}$ The utility of a manager who quits a firm is therefore independent of that firm's future performance. This is not the case in our model, because the manager's reputation may be affected by the firm's future performance even after he stopped working for that firm.

Let us now turn to the firm's optimal employment policy. For sake of consistency, we need to make an assumption on the model parameters to ensure that, given the wages determined in Proposition 1, shareholders want to induce effort at the first period.

\section{Assumption 1}

$$
R^{h}-R^{l} \geq \frac{\bar{e}_{2}}{\Delta e_{2}} \cdot \frac{c}{p^{l} \Delta e_{2}} .
$$

Assumption 1 provides a sufficient condition for shareholders to induce high second period effort, for any first-period payoff. Note that this condition is stronger than the first best condition (1). This is because incentivizing managers is costly: the difference in returns between the high and low states must be high enough to cover the agency rent.

Proposition 2 If the manager has any reputational concerns, the only renegotiation proof employment policy is to retain the manager at date 1 , regardless of his performance.

This statement follows straightforwardly from the comparison of the second period wage payments given in equations (5) and (6). Suppose the firm observes poor interim performance $R_{l}$. At that stage it has the choice of retaining the manager and paying wage $w_{\text {old }}^{l, h}$ in case of subsequent success, or hiring a new manager and paying $w_{\text {new }}^{l, h}>w_{\text {old }}^{l, h}$. Since the identity of the manager has no

\footnotetext{
${ }^{18}$ Oyer (2004) is an exception to this. He focuses on the role of absolute performance based compensation in adjusting wage to the CEO's changing outside opportunities.

${ }^{19}$ An exception to this is Gorton and Grundy (1997) who point to a related free rider problem in a model where managers need to be given explicit long-term wage payments. Hence, managers in their model may free ride because they benefit via explicit wage payments if the firm's future performance is strong even if they quit the firm.
} 
impact on performance the firm clearly prefers to retain the manager. Moreover, the manager also prefers to remain with the firm, because it allows him to earn the agency rent in the next period. Note that at the interim stage, the firm is indifferent between retaining and firing the manager after good performance. However, we show below that committing to retain the manager after good interim performance is ex ante optimal. The optimal renegotiation-proof contract will thus entail retaining the manager after good interim performance.

Proposition 2 contains the key result on entrenchment. It states that a policy of firing the manager after poor interim performance is time inconsistent because employing a new manager is more expensive than retaining the incumbent manager, without yielding any benefit to the firm after date 1. Note that this result holds even though the incumbent has no productivity advantage over a newly employed manager, which is what usually underlies stories of entrenchment (e.g., Shleifer and Vishny (1989) or Crémer (1995)).

\section{B. Optimal first period wages}

Let us now complete the characterization of wage contracts by solving for the optimal first period compensation scheme. Since the manager is always retained at the interim date, it is easy to write down his first period incentive compatibility constraint. The resulting optimal first period payments are given in the following Lemma.

LEMMA 1 Under the optimal renegotiation proof contract, the manager's first period wage is given by

$$
\begin{aligned}
w^{h} & =\max \left[0, \frac{c}{q_{0} \Delta e_{1}}-\bar{e}_{2}\left(w^{h, h}-w_{\text {old }}^{l, h}\right)-\left(1-\bar{e}_{2}\right) \Delta f\right] \\
w^{l} & =0
\end{aligned}
$$

where $w^{h, h}$ and $w_{\text {old }}^{l, h}$ are given in Proposition 1.

The explicit first period incentive payment $w^{h}$ depends on two kinds of incentives: the size of the second period agency rent and reputational concerns. Since the manager is retained after poor performance, he will earn an agency rent in the next period even though he performs badly. This affects negatively his first period incentives and increases $w^{h}$. On the other hand, the agency rent he earns when being retained after good first period performance provides an additional incentive at the first date to exert effort: $w^{h}$ decreases with $w^{h, h}$. For this reason, it is optimal ex ante to commit to retain the manager after good performance, even if shareholders are ex post indifferent between retaining the incumbent manager and hiring a new one. ${ }^{20}$ The second type of incentive stems from reputational concerns. If the manager achieves a high cash flow at the first date he

\footnotetext{
${ }^{20}$ The fact that future rents enhance present incentives to effort is well-known in dynamic moral hazard models, and goes back to Rogerson (1985). Our model brings new insight by explaining why future rents can have countervailing effects on incentives because shareholders also prefer to retain managers after bad performance.
} 
improves his reputation and this by itself provides an implicit incentive to exert effort. But this effect is attenuated by the manager's opportunity to restore his reputation after bad performance.

\section{The cost of entrenchment}

An important question that arises once we know the full solution to the contracting problem is whether the type of entrenchment identified above actually carries any cost to the firm. Entrenchment arises because the firm is unable to commit credibly to a policy of firing the manager at the interim date. It would always want to renegotiate such a contract and retain the manager instead, even if he performed poorly. As a result it cannot credibly use the threat of dismissal to provide first period incentives to the manager. Note that this contrasts with other results in the literature on dynamic contracting, e.g., v. Thadden (1995) and Almazan and Suarez (2003). In those papers the firm's interim efficient decision may be to liquidate the firm (v. Thadden) or fire the manager (Almazan and Suarez), and this may reduce the manager's ex ante effort incentives. In those papers there is therefore a role for long-term contracts that bind the firm to retaining the manager at the interim date. In our model such contracts do not help, because the firm's interim efficient decision already involves retaining the manager more often than may be ex ante desirable.

We now identify what would be the gain in firm value if shareholders could commit ex ante to an employment policy (e.g. to firing the manager, if it is optimal to do so).

Proposition 3 If the shareholders can commit to an employment policy, the ex ante expected firm value increases by:

$$
q_{0} \max \left[\bar{e}_{1}\left(w^{h}-\hat{w}^{h}\right)-\left(1-\bar{e}_{1}\right) \bar{e}_{2}\left(w_{\text {new }}^{l, h}-w_{\text {old }}^{l, h}\right) ; 0\right],
$$

where $w_{\text {new }}^{l, h}$ and $w_{\text {old }}^{l, h}$ are defined in Proposition $1, w^{h}$ in Lemma 1 and

$$
\hat{w}^{h}=\max \left[0, \frac{c}{q_{0} \Delta e_{1}}-\left(\bar{e}_{2} w^{h, h}-c\right)-\left(1-\bar{e}_{2}\right) \Delta f\right] .
$$

Proposition 3 states that the ability to commit ex ante to an employment policy is not necessarily valuable for shareholders. It is valuable only if (10) is positive. Put differently, it is sometimes optimal from an ex ante point of view to retain the manager after bad performance. Expression (10), where $\hat{w}^{h}$ represents the first period wage of the initial manager, if he is fired after bad performance, illustrates clearly the trade-off faced by shareholders. On the one hand, committing to firing the poorly performing original manager increases the second period wage expenses, because it is more costly to incentivize a new manager, with no reputational concerns. This extra cost is measured by $\left(1-\bar{e}_{1}\right) \bar{e}_{2}\left(w_{\text {new }}^{l, h}-w_{\text {old }}^{l, h}\right)$. On the other hand, when the original manager is fired if he performs badly, it is easier to incentivize him at the first period, which reduces expected wage expenses by $\bar{e}_{1}\left(w^{h}-\hat{w}^{h}\right)$. Whether committing to firing the original manager is beneficial to shareholders depends on which effect dominates.

In our model where incentives can be given by reputational concerns, wages might turn out to be equal to zero. Intuitively, this will be the case if reputational concerns are large. To highlight the 
interaction between implicit and explicit incentives, and to focus on the most realistic cases where managers need also positive wages to be incentivized, we assume that first-period wages are strictly positive. Since $\hat{w}^{h}<w^{h}$, we simply need to ensure that $\hat{w}^{h} \geq 0$, which is true under assumption 2 :

\section{Assumption 2}

$$
\Delta f \leq \frac{c\left(\frac{1}{q_{0} \Delta e_{1}}-\frac{e_{2}}{\Delta e_{2}}\right)}{1-\bar{e}_{2}} .
$$

Using assumption 2, as well as the wage values determined before, one can determine the net benefit of committing to an employment policy.

COROLlaRY 2 Under assumption 2, if the incumbent manager's wage $w_{\text {old }}^{l, h}$ is determined by his binding participation constraint, the net benefit of committing to an employment policy is equal to:

$$
\frac{q_{0} c}{p^{l} \Delta e_{2}} \max \left[\Delta e_{2}\left(1-\bar{e}_{1} p^{l}\right)-\bar{e}_{2}\left(1-\bar{e}_{1}\right) ; 0\right] .
$$

If $w_{\text {old }}^{l, h}$ is determined by the incumbent manager's binding incentive compatibility constraint, it is equal to:

$$
q_{0} \max \left[\bar{e}_{1} \bar{e}_{2} \frac{c}{p^{l} \Delta e_{2}}-\bar{e}_{2} \Delta f-\bar{e}_{1} c ; 0\right] .
$$

Suppose the second period wage when the manager is retained is determined by the binding participation constraint. Then from (12) we can see that the cost of entrenchment depends on the likelihood $p^{l}$ with which the good strategy $S=G$ is being operated conditional on having observed poor performance $R_{l}$. Note that the manager is indifferent between being retained and being fired conditional on the realization $R_{l}$. One might therefore expect firing, and the threat thereof, to do nothing to incentives. This, however, is not the case, because the manager's actual payoff differs depending on whether the operating strategy is $G$ or $B$. In particular, if $S=G$ then the manager strictly prefers to be retained, even if his participation constraint is binding. Conversely, he would strictly prefer to quit if he knew that $S=B$. His actual wage is set to make him indifferent conditional on $R_{l}$ only and is thus a probability weighted average between an expected payoff conditional on $S=G$ and $S=B$. Since his first period incentives are only affected by his payoffs when the strategy is $S=G$ the threat of losing the rent when $R_{l}$ occurs provides an implicit incentive to exert effort at the first date. The lower $p^{l}$ the more he benefits from being retained conditional on $S=G$ and the stronger are the incentive implications from a threat of firing. The benefit to the firm from being able to commit to firing the manager after poor performance is therefore higher when $p^{l}$ is lower.

Suppose instead that the second period wage of the retained manager is determined by the binding incentive compatibility constraint. Then the firm's ex ante value increases when using the threat of dismissal only if reputational concerns are not too high. Consider the benchmark case when there are no reputational concerns, i.e., $\Delta f=0$. In that case the firm would certainly want to make use of the threat of dismissal, to mitigate the managerial moral hazard problem. 
From expression (13), one can see that the net benefit of committing to firing the manager is then positive. But when the manager cares a lot about his reputation, the reduced cost of first period wages may be outweighed by the additional cost of replacing the manager at the second date. The firm would then not benefit from committing to fire a poorly performing manager.

\section{Interim Strategy Change}

In the above analysis it has been assumed that the strategy choice could not be altered throughout the lifetime of the project. We now extend the analysis to the case where the firm can choose to abandon the strategy that was started in favour of the alternative, untested strategy. By construction, the success or failure of the new strategy throws some light on whether the original strategy choice was good or bad. This new set-up extends our earlier notion of a managerial legacy. The manager's reputation is affected in the longer term by an earlier strategic choice, even if the strategy has been changed in the meantime, and even if the manager no longer works for the firm.

The kind of situation we have in mind is one where a firm faces a major strategic decision and a CEO takes the initiative to make that choice. If the firm's subsequent performance is poor, it may wish to abandon this strategy and instead go for 'the obvious alternative' strategy that had been rejected initially. Note that the decision to change strategy is now relatively mechanical and per se does not require a CEO to develop a new strategic vision, although it requires effort to implement the alternative strategy successfully. In the example of DaimlerChrysler developed in the introduction, while the World Inc strategy was really Schrempp's vision, the decision to abandon the worldwide expansion, and to refocus on the firm's core competencies (making high quality cars) was taken by the board (for example, the decision to retreat from Asia was taken while Schrempp was still in place, against his advice). ${ }^{21}$

To investigate the joint decision to change strategy and possibly manager, we now assume that the firm can switch strategy at the interim date. First period cash flows are distributed exactly as described in Section IV. Second period cash-flows still depend on whether the good or the bad strategy is implemented. Therefore, if the firm sticks to the original strategy, the second period cash flow distributions are exactly as described in Section IV. If the firm switches, the cash flow distribution depends on the quality of the strategy that is being implemented in the second period. If the firm implements the bad strategy at the second date, its payoff is $R_{l}$ with certainty. If it implements the good strategy it is $R_{h}$ with probability $e_{2}$ and $R_{l}$ with probability $1-e_{2}$.

To derive the optimal strategy/manager choice, we first determine the optimal employment policy for each interim strategy choice, and then conclude on the optimal strategy choice.

\footnotetext{
${ }^{21}$ Boot (1992) and Prendergast and Stole (1996) implicitly provide another reason for leaving this decision to the board and not the CEO: If the latter makes a strategy recommendation based on private information, he may have an incentive to report in favor of the strategy originally chosen by him. We assume, however, that the manager has no superior information about the quality of the strategy, and therefore this issue does not arise.
} 


\section{A. Choice of manager given the choice of strategy}

The firm's interim decision problem is now more complicated, because it needs to decide simultaneously (i) which strategy to pursue, (ii) with which manager to pursue it, and (iii) what wage contract the chosen manager should be offered. To account for all these possibilities, the wage contracts will be generically written: $w_{\text {choice,manager }}^{i, j}$ where the variable 'choice' can be 'stick' or 'switch' and the variable 'manager' can be 'old' or 'new'. For example, $w_{\text {stick,old }}^{l, h}$ represents the wage offered to the original manager if the firm sticks to the initial strategy, retains the original manager, and generates cash-flows $R^{l}$ at $t=1$ and $R^{h}$ at $t=2$.

The following proposition establishes the optimal employment policy, given the firm's decision to switch strategy.

Proposition 4 If the firm wants to switch strategy at the interim date, it is optimal to hire a new manager, i.e. $w_{\text {switch,old }}^{l, h} \geq w_{\text {switch, new }}^{l, h}$.

According to Proposition 4 the firm will never pursue a new strategy with the incumbent manager. The intuition for this result is as follows. The incumbent manager's reputation is tied to the success of the strategy that he chose. Success of the new strategy therefore implies that the manager's original strategy choice was poor. This gives the manager an inherent interest in making the new strategy fail, which would be interpreted as a vindication of his original choice. As a result the incumbent manager has an incentive not to put effort into implementing the new strategy. The firm can overcome this bias if it provides sufficiently strong explicit incentives. This, however, is more expensive than simply hiring a new manager, who has no vested interest in the firm's chosen strategy. Thus, the same reputational concerns that made it cheap to employ the incumbent manager to implement the original strategy, now make it expensive to employ him to implement a new strategy. The only case where the incumbent manager is equally well suited as a new manager to implement the new strategy, is when he has no reputational concerns at all.

This result is important, because it characterizes the reason why in practice there is frequently a close association between a particular strategy and the manager who implements it. We depart from the standard assumption that managers have an inherent productivity advantage with regards to a particular strategy (e.g., Shleifer and Vishny, 1989). Managers in our model have no such productivity advantage, but they happen to implement only those strategies that they have chosen originally. This is because an association between the cost of incentivizing a manager and the type of strategy he implements arises endogenously from the manager's reputational concerns. It would in principle be straightforward to require from the agent that he accept a strategy change after poor performance and implement the new strategy. This, however, would make it difficult for the manager to be genuinely interested in seeing the strategy succeed.

We now derive the optimal employment policy when the firm decides to stick to the original strategy. Note that even in that case, the incumbent manager's wage is affected by the ability to change strategy. Indeed, the possibility to switch strategy affects the manager's interim partici- 
pation constraint compared to the case where no such change is possible, because the distribution of the manager's reputation depends on the firm strategy choice were the incumbent manager to resign. The optimal wage contract for the incumbent is derived in the following Lemma.

LEMma 2 If the firm sticks to the initial strategy :

(i) If $p^{l}<\frac{1}{2}$, then the incumbent's second period wage contract is given by

$$
\begin{aligned}
w_{\text {stick,old }}^{l, h} & =\max \left\{\frac{c}{p^{l} \Delta e_{2}}-\Delta f, \frac{c}{p^{l} \bar{e}_{2}}+K\right\}, \\
w_{\text {stick }, \text { old }}^{l, l} & =0,
\end{aligned}
$$

where

$$
K=\frac{f\left(q_{\text {switch }}^{l, l}\right)-f\left(q^{l, l}\right)}{p^{l} \bar{e}_{2}}-\Delta f-\frac{1-p^{l}}{p^{l}}\left(f\left(q_{\text {switch }}^{l, l}\right)-f(0)\right) .
$$

(ii) If $p^{l} \geq \frac{1}{2}$, then $w_{\text {stick,old }}^{l, j}$ is given by (6).

As before, the incumbent manager's wage may be determined by either a binding (IC) constraint, or his participation constraint. The (IC) constraint is exactly as before, but the manager's participation constraint changes when $p^{l}<\frac{1}{2}$. Whether it is now easier or harder to satisfy, depends on the sign of $K$. Overall, the choice with which manager to continue, depends on the parameters as follows.

Proposition 5 If the firm sticks to the initial strategy after bad interim performance $R^{l}$, then

- if $p^{l} \geq \frac{1}{2}$, it is optimal to retain the original manager,

- if $p^{l}<\frac{1}{2}$, it is optimal to retain the original manager if the probability of success is sufficiently large, in the sense that:

$$
\bar{e}_{2}>\frac{f\left(q_{\text {switch }}^{l, l}\right)-f\left(q^{l, l}\right)-\frac{\underline{e}_{2} c}{\Delta e_{2}}}{p^{l} \Delta f+\left(1-p^{l}\right)\left(f\left(q_{\text {switch }}^{l, l}\right)-f(0)\right)},
$$

and hire a new manager otherwise.

When $p^{l} \geq \frac{1}{2}$ or when $p^{l}<\frac{1}{2}$ and $\bar{e}_{2}$ is sufficiently high, ${ }^{22}$ the second period wage of the original manager is lower than that of a newly hired manager. Our previous result on entrenchment still holds.

When $p^{l}<\frac{1}{2}$ but $\bar{e}_{2}$ is small, then the probability of failure is high regardless of whether the right or the wrong strategy was used. The cost of a strategy change is therefore low for the original manager. On the other hand, he benefits from the small but likely improvement in his reputation when the strategy is changed and unsuccessful. Hence, the 'threat' of changing the strategy when

\footnotetext{
${ }^{22}$ Note that the right-hand side of condition $(14)$ is smaller than one, so that there is always a parameter for which this is true.
} 
the manager resigns is not always effective. As a consequence, his participation constraint may become harder to satisfy, and this could make it cheaper to hire a new manager to implement the old strategy. Although we cannot exclude it, we view this possibility as rather remote, because it can only occur if the probability of successful project implementation is extremely low (condition (14) needs to be violated). For instance, if the value of reputation is linear in $q$ (i.e., $f(q)=a q$ ), then (14) is always satisfied and the above case never happens. The ability to change strategy then does not modify wages, and the incumbent manager is entrenched.

\section{B. Optimal strategy change}

The full solution to the firm's problem requires determining when it is optimal to change strategy. The firm makes this choice after observing first period performance so as to maximize expected firm value net of wage payments, subject to the incentive compatibility and participation constraints of the manager it wishes to employ. Trivially, it is never optimal to change strategy after good first period performance, since it is then known that the strategy was indeed good. This raises the question under what conditions a strategy change should occur after poor performance $R_{l}$. In the absence of an agency problem, the firm should switch strategy if the probability of the good strategy after a change is higher than without a change. In our model, this is the case whenever $p^{l}<\frac{1}{2}$.

The following Proposition states when it is optimal to change strategy in the presence of an agency problem.

Proposition 6 It is optimal for the firm to continue with the old strategy after poor first period performance $R_{l}$ if $p^{l} \geq p^{*}$, where

$$
p^{*}=\frac{1}{2}-\frac{\left(1-p^{l}\right) w_{\text {switch,new }}^{l, h}-p^{l} w_{\text {stick }}^{l, h}}{2\left(R_{h}-R_{l}\right)}
$$

and to change strategy otherwise.

The optimal point at which a switch in strategy should occur, changes in the presence of an agency problem. This is because the wage payments depend on which strategy is continued.

COROllary 3 If (14) holds (it is optimal to retain the initial manager when the firm wishes to continue its original strategy) then $p^{*}<\frac{1}{2}$. Otherwise $p^{*}=\frac{1}{2}$.

When $p^{*} \leq p^{l}<\frac{1}{2}$ the firm hangs on to the old strategy even though it knows that the other strategy is more likely to be the right one. This is because the wage payment required for the incumbent manager to exert effort to implement the original strategy is lower than the wage payment required for the new manager to do so with the new strategy. It follows that shareholders are reluctant to change strategy. Hence, the firm switches strategy less often than would be optimal without agency problems. The firm exhibits inertia in adopting a new strategy. 
Moreover, the gap between expected wage payments $p^{l} w_{\text {stick,old }}^{l, h}$ under strategy continuity and a change in strategy $\left(1-p^{l}\right) w_{\text {switch,new }}^{l, h}$ becomes more pronounced if the incumbent manager has stronger reputational concerns. The higher the reputational concerns of the manager, the stronger the bias towards sticking to the old strategy. In the extreme opposite case where there are no reputational concerns the firm's decision to change strategy would be unaffected by the agency problem and the optimal threshold would be $p^{l} \geq p^{*}=\frac{1}{2}$.

Strategy inertia occurs whenever it is cheaper to retain the incumbent manager than to hire a new manager to implement the old strategy, i.e. when condition (14) in Proposition 5 holds. Corollary 3 does not rule out the possibility that, even in the presence of reputational concerns, the firm does not exhibit inertia. This however only happens for a small, and rather non typical, set of parameters ${ }^{23}$ for which it is optimal to hire a new manager even when the firms decides to continue the old strategy (i.e. when condition (14) does not hold).

\section{Interpretation of wage contracts and empirical implications}

In this Section we derive some empirical implications supported by our analysis, discuss their relevance to address actual empirical findings, and propose new possible empirical tests. To formulate these predictions, we first need to characterize how the optimal wage can be implemented.

\section{A. Rationale for the repricing of stock-option schemes}

We now investigate how the wage contracts derived above may be implemented using simple financial instruments, like stock options. To do that, we focus on the renegotiation proof contracts, whereby if $p^{l} \geq p^{*}$ defined in Proposition 6, the incumbent manager is retained, while he is fired, and the strategy is reversed, if $p^{l}<p^{*}$. The following proposition summarizes what can be achieved with stock options.

PROPOSITION 7 The first period wage contract can be implemented by granting the manager shortterm stock options.

If $p^{l}<p^{*}$, the second period wage contract can be implemented by granting the new manager shortterm stock options.

If $p^{l} \geq p^{*}$, the second period wage contract can be implemented by granting the manager long-term stock options, that will be repriced at the interim date in case of bad performance.

The Proof of Proposition 7 follows in the text below. The implementation described in the Proposition is of course not unique, and we do not attempt to provide an argument for the use of stock options in general. It is helpful though to see whether the wage contract dynamics that we derived earlier are compatible with observed patterns. Firstly, note that the optimal wage contracts are path dependent and therefore they can neither be implemented by making wage conditional on

\footnotetext{
${ }^{23}$ Recall for instance that for linear reputation functions, this case never happens. For other functional forms, the probability of success in the second period $\bar{e}_{2}$ must be very low.
} 
current cash flows alone, nor by making them contingent on cumulative cash flows. ${ }^{24}$ Intuitively, awarding stock options that are repriced after poor performance is then a way of implementing the path dependence implied in optimal wage contracts. ${ }^{25}$

To fix ideas, assume that the firm does not distribute any dividends at $t=1 .^{26}$ The firm value, and the stock price, is simply the sum of the accumulated cash flows. Denote $P_{i}$ the firm's date 1 stock price when cash flow is $R_{i}$, and $P_{i+j}$ the firm's date 2 stock price when cash flows are $R_{i}$ and $R_{j}$. The implementation of the first period wage is then straightforward. The first period wage contract (see Lemma 1) rewards the manager in a particular period only if the firm's performance in that period is strictly above $R_{l}$. Such a payoff structure can be achieved by issuing $x_{1}$ stock-options with exercise price $X_{1}$ such that:

$$
\left\{\begin{array}{ccc}
X_{1} & > & P_{l} \\
x_{1}\left(P_{h}-X_{1}\right) & = & w^{h} .
\end{array}\right.
$$

The same reasoning applies for the second period wage, if a new manager is hired following poor performance: his wage contract is implemented by granting him $x_{2}$ stock-options with exercise price $X_{2}$ such that:

$$
\left\{\begin{array}{ccc}
X_{2} & > & P_{l+l} \\
x_{2}\left(P_{l+h}-X_{2}\right) & = & w_{\text {new }}^{l, h} .
\end{array}\right.
$$

If the incumbent manager is retained, the second period wage depends also on the history of cash-flows $\left(w_{\text {old }}^{l, h} \neq w^{h, l}\right)$. This precludes issuing standard long term stock options: these claims depend only on the total firm value, which is the same whether a high cash flow follows a low cash flow or vice-versa. To implement the optimal contract, the firm can issue at $t=0, y$ long term stock options, with initial exercise price $Y$ exercisable at $t=2$, such that:

$$
\left\{\begin{array}{ccc}
Y & > & P_{l+h} \\
y\left(P_{h+h}-Y\right) & = & w_{\text {old }}^{h, h} .
\end{array}\right.
$$

The first condition says that the stock-options expire worthless when the firm value is $R_{l}+R_{h}$, and the second says that the manager obtains exactly $w^{h, h}$ when the firm value is $2 R^{h}$. If $R^{l}$ occurs, stock options are repriced to $\widehat{Y}<Y$ such that:

$$
\left\{\begin{array}{ccc}
\widehat{Y} & > & P_{l+l} \\
y\left(P_{l+h}-\widehat{Y}\right) & = & w_{\text {old }}^{l, h}
\end{array}\right.
$$

At the interim date, if the cash-flow is low, the long term stock-options are repriced (by lowering the exercise price), so that they have a positive value if a high cash-flow occurs at the second period.

\footnotetext{
${ }^{24}$ The first point follows directly from the fact that wages at date 2 are a function of prior performance, i.e., $w^{h, h} \neq w^{l, h}$. The second point follows from $w^{h, l} \neq w^{l, h}$.

${ }^{25}$ Alternatively, path dependence can be achieved by granting a sequence of short-term options that are always issued at the money and thus take into account interim stock price changes of the firm. Issuing at-the-money stock options is in line with observed firm practice.

${ }^{26} \mathrm{Or}$, to be less restrictive, that the dividend payment is independent of the cash flow.
} 
Acharya, John and Sundaram (2000) also show that path dependent contracts can be implemented using executive stock options with revisions in strike price. In contrast to our paper they do not consider the case where the firm has a choice between repricing the options of a retained manager and simply firing the manager after poor interim performance. Taking this choice into account allows us to derive new empirical implications that consider explicitly stock-options repricing, CEO turnover, and strategic decisions.

\section{B. Predictions}

The main prediction of our analysis is that there should be a positive correlation between strategic continuity and managerial retention. This link should be stronger when reputational concerns are important and when firms face long-term strategic decisions. Similarly, we would expect retention and thus stock option repricing following poor performance to be more prevalent when these two conditions are satisfied. To be able to test this prediction, one should find proxies for reputational concerns and for the importance of long-term strategic choice. The most obvious determinant of reputational concerns is the manager's age. Moreover, to the extent that one's reputation is more easily established in a younger firm where the manager's choice of strategy is a key element of success, the firm age could be a further determinant of reputational concerns. In addition, it is likely that new firms in high tech or innovative sectors face important long-term strategic decisions, which could constitute a proxy for the prevalence of long term strategic decisions. We therefore expect the positive relation between managerial retention, strategic inertia (or continuity) and repricing to be stronger for young and/or high-tech, innovative firms.

Since to our knowledge, no empirical study has investigated the joint determination of firm employment policy, CEO compensation package and strategic decision, it is hard to determine whether our predictions are consistent with existing empirical work. We can however from our general implications, derive 'partial' predictions consistent with the data. Although other theories can account for some of these results, no single alternative theory can encompass all of them. For this reason we believe that our model can shed new light on these issues.

A first set of implications of our model addresses the decision to reprice stock-option schemes.

- Our analysis predicts that there should be more turnover for established firms, and more repricing for young firms. Repricing should also be more prevalent in firms that are in a phase of taking long-term strategic decisions and where the legacy concerns are likely to be more important. Several empirical studies speak directly to these predictions. Brenner, Sundaran and Yermack (2000) and Chance, Kumar and Todd (2000) both find that repricing firms tend to be smaller, while Chidambaran and Prabhala (2003) find that repricers are concentrated in young firms in technology sectors. Moreover, Bizjak, Brickley and Coles (1993) and Joos, Leone and Zimmermann (2003) find that high-growth and start-up firms hire younger CEOs, i.e., CEOs who one might expect to have stronger reputational concerns. Managerial legacies and option repricing may therefore feature more prominently in those firms. 
- The purpose of the repricing of stock-option plans should be to retain managers when reputational concerns are prominent, while it should be to incentivize managers when reputation concerns are less important. Chen (2004) provides empirical evidence that firms which restrict themselves not to reprice executive stock options have higher managerial turnover and concludes that stock option repricing is used systematically by firms for the purpose of managerial retention. He also finds that the repricing policy affects the sensitivity of managerial turnover with respect to stock price movements more strongly for non-CEO managers. Our paper does not attempt to model incentives for non CEO managers and therefore cannot speak directly to this evidence. However, Chen's finding is consistent with our notion that more junior managers, who can be expected to have more reputational concerns are more likely to resign from the firm if their options are not repriced.

Second, our analysis provides insights into the determinants of strategy change.

- A consequence of our model is that the incumbent CEO displays a commitment to the status quo. A possible prediction of our model is that managerial replacement should be closely associated with major changes in the firm's strategy. Because CEO replacement can also be motivated by a variety of reasons, one way to test the above prediction is to investigate whether there are more changes in firms' strategy after forced replacement of CEOs compared to voluntary departures.

- The incumbent manager's bias towards the status quo renders a change in strategy costly to the firm. We thus expect strategic inertia to be prevalent when reputational concerns are important. From the discussion above, we can conclude that young, and/or technology firms may exhibit a tendency not to adapt easily once their strategic plan is adopted. Our results thus predict a stronger link between strategic continuity, and managerial retention for young and/or technology firms.

- Strategic change can also be captured by capital reallocation inside or between firms. The change in strategy in our model can be interpreted as the redeployment of existing assets to a more profitable alternative use, or can involve the sale of existing assets, if such redeployment inside the firm is not possible. We showed that reputational concerns can impede capital reallocation to more productive uses. Another prediction of the model is that (otherwise beneficial) capital reallocations should be less frequent, the stronger the reputational concerns of firms.

Although not directly tested, the above predictions are consistent with some empirical observations. For instance, Romanelli and Tushman (1994) find empirically that CEO turnover increases the probability to engage in strategic change in the minicomputer producers industry. This result is also supported by Lant and Milliken (1992), and Gordon, Stewart, Sweo and Luker (2000) in the furniture and computer software industries. More importantly, both Romanelli and Tushman (1994), and Gordon et al. (2000) find no direct evidence that poor past performance per se affects 
the probability of strategic reorientation. This is consistent with our findings that i) firms exhibit strategic inertia and do not respond necessarily to poor performance by changing strategy, and ii) a strategy change is implemented by changing manager.

In a recent paper, Dass (2006) explores the determinants of major changes in a firm's book to market ratio. He finds that a CEO change is a strong predictor for a firm's subsequent drastic B/M change. Moreover, he provides evidence that those changes are correlated with the book to market ratio of the firm that the new CEO managed prior to changing firms. This is consistent with our notion that managers are tied to specific 'styles' (strategies) through their reputational concerns.

Last, Eisfeldt and Rampini (2005) study the cyclical properties of capital reallocations, and find that the benefits of capital reallocation are fully exploited during booms, while they are not during recessions. ${ }^{27}$ According to the authors, this suggests more contractual or informational frictions during recessions (see also Eisfeldt and Rampini, 2004). Our model identifies one possible contractual friction between managers and firms, whose strength may be affected by the stage of the business cycle: in periods of recessions, profits are generally low and good investments opportunities are scarce. Successful projects are more easily attributable to managers' skills, which gives rise to more reputational concerns. Moreover, if we think of reputational concerns as the expected present value of deferred compensation, then during recessions the balance between deferred and contemporaneous compensation is likely to shift towards deferred compensation. In other words reputational concerns become more important. Shareholders are then more reluctant to reallocate capital and large differences in capital productivity emerge.

\section{Extensions}

\section{A. Reputational concerns at other levels of the organization}

It is likely that the kinds of considerations explored above are relevant at all levels of an organization and not only for the CEO. Non-executive directors, for example, may care about a good reputation, because it allows them to secure directorship appointments with other firms. Probably the single most important decision of the non-executive directors is to choose and appoint a good CEO - and replacing him if the situation calls for it. Firing the CEO, however, amounts to admitting an earlier mistake with associated reputational costs for non-executive directors. As a result, the board may be reluctant to fire an underperforming CEO, which further strengthens the results of the paper.

Similarly, a manager working for the incumbent CEO may have some reputational capital tied up with the CEO's decisions. This may affect the decision whether to replace a departing CEO with an inside- or an outside appointment. If the company wishes to continue with its existing strategy, it might prefer an inside appointment, who will to some extent share responsibility for the strategies in place and therefore be more strongly motivated to make those strategies succeed than an outsider. Similarly, if the company wishes to undertake a major strategy change, it might prefer

\footnotetext{
${ }^{27}$ Specifically, they find evidence that the dispersion in capital productivity across firms is countercyclical, while the amount of capital reallocation is procyclical.
} 
an outside appointment in order to avoid an adverse incentive effect from which an insider would suffer. One clear prediction coming out of our theory is that outside appointments should receive higher salaries than inside successors: the latter are more strongly incentivized by reputational concerns and therefore do not need to be paid quite as much as outsiders. This is consistent with the empirical finding in Murphy (2002) that outside successors' first year compensation is almost twice that of inside successors.

\section{B. The role of takeovers}

In the model presented before, the firm's choice at the interim date was to either retain the incumbent manager or to fire him and hire a new manager. While new managers have reputational concerns, they are not incentivized by those concerns when they take over from another manager who left behind his legacy. This, however, may be different if the pool of available new managers includes ones that have made related strategic choices in other firms. Suppose for example that firm 1's manager has initially chosen strategy X, while firm 2's management chose strategy Y instead. If firm 1 performs poorly and wishes to change to strategy $\mathrm{Y}$ it may wish to do so with a manager who has a vested interest in seeing strategy $\mathrm{Y}$ succeed. ${ }^{28}$ Such a manager would be driven by reputational concerns and therefore command a lower explicit wage payment.

If it is cheaper in this way for firm 2's manager to run both firm 1 and firm 2, it would seem that firm 2 taking over firm 1 would be efficiency improving. Moreover, the incumbent manager of firm 1 would typically oppose such a takeover, because he would lose his agency rent in the second period, or because changing the strategy would reduce the expected value of his reputation (when (14) holds). This can help explain why some takeovers are hostile even though they do not directly serve a disciplinary function. Franks and Mayer (1996) for example find that hostile takeovers in the UK are not primarily driven by a desire to discipline poorly performing management, but are associated with high levels of asset redeployment. According to our story a takeover does not serve the purpose of disciplining management - the board can do that without the help of a hostile raider. Instead, the takeover is driven by a desire for a major strategy change that is difficult to implement under the existing management. This allows us to make a prediction about the type of bidding firms in hostile acquisitions, namely that they should be firms that operated a related business, but employed a different strategy from that of the target firm. The takeover then serves the purpose of modifying the strategic outlook of the target firm.

\section{Conclusions}

This paper explores a firm's decision to replace a poorly performing CEO with a new CEO in a context where strategic decisions have a long-term impact on the firm's cash flows. The long-term nature of the firm's strategy means that a new CEO's performance is partially affected by something

\footnotetext{
${ }^{28}$ Modeling this effect is somewhat involved, because the introduction of a second firm raises the issue of relative performance evaluation - an issue we do not want to pursue here.
} 
he bears no responsibility for, namely the previous CEO's choice of firm strategy. This renders the incentive problem of a new CEO more severe than it would be for the incumbent CEO. As a result the firm will not always wish to fire the CEO even if he performs poorly - the incumbent is entrenched. We also show that the resulting lack of a credible threat to dismiss the CEO after poor performance can be costly for the firm.

We extend the model to allow for strategy changes by the firm at the interim date. Doing so allows us to study the links between managers and strategic choices. We show that strategy change and managerial turnover are closely associated, and that the (endogenous) cost of managerial turnover makes it more expensive for the firm to change strategy. This leads to 'strategic inertia' in the firm's decision.

Our model throws new light on the empirically puzzling observation that poorly performing CEOs are often retained and even get their stock option incentive contracts repriced, further undermining any punishment the firm inflicts in response to poor performance. We identify two reasons for repricing: refreshing the CEO's incentives and making sure that the CEO does not quit the firm. Existing literature found it hard to explain why firms should have to worry about their ability to retain a CEO who performed poorly. We show that a CEO may have a valuable outside option even after poor performance, because his reputation can be rehabilitated by a future generation of managers. 


\section{Appendix}

\section{Proof of Proposition 1}

The optimal second period wages maximize the shareholders' expected payoff subject to the participation and incentive compatibility constraints of managers. We determine the optimal wages if shareholders want to induce effort at $t=1^{29}$. We will provide sufficient conditions for this to be the case. Given this assumption, the shareholders's expected payoff is simply the firm's expected cash flow given high effort, minus the expected wage payment. To maximize profits, one simply needs to minimize expected wages.

The constraints to consider are the following.

First, if he is retained, the incumbent manager must be induced to exert effort at $t=1$. His incentive compatibility constraint is generically written as:

$$
\begin{array}{r}
p^{i}\left(\bar{e}_{2}\left(w^{i, h}+f\left(q^{i, h}\right)\right)+\left(1-\bar{e}_{2}\right)\left(w^{i, l}+f\left(q^{i, l}\right)\right)\right)+\left(1-p^{i}\right)\left(w^{i, l}+f\left(q^{i, l}\right)\right)-c \geq \\
p^{i}\left(\underline{e}_{2}\left(w^{i, h}+f\left(q^{i, h}\right)\right)+\left(1-\underline{e}_{2}\right)\left(w^{i, l}+f\left(q^{i, l}\right)\right)\right)+\left(1-p^{i}\right)\left(w^{i, l}+f\left(q^{i, l}\right)\right),
\end{array}
$$

which can be rewritten as:

$$
w^{i, h}-w^{i, l} \geq \frac{c}{p^{i} \Delta e_{2}}-\left(f\left(q^{i, h}\right)-f\left(q^{i, l}\right)\right)
$$

The incentive compatibility constraint of a newly hired manager takes into account the fact that his reputation is not affected by the second period cash flows. It is written as:

$$
\begin{aligned}
p^{i}\left(\bar{e}_{2} w^{i, h}+\left(1-\bar{e}_{2}\right) w^{i, l}\right)+\left(1-p^{i}\right) w^{i, l}-c & \geq \\
& p^{i}\left(\underline{e}_{2} w^{i, h}+\left(1-\underline{e}_{2}\right) w^{i, l}\right)+\left(1-p^{i}\right) w^{i, l},
\end{aligned}
$$

which can be written as:

$$
w^{i, h}-w^{i, l} \geq \frac{c}{p^{i} \Delta e_{2}}
$$

Second, we must ensure that the incumbent manager prefers to stay in the firm, rather than resign at $t=1$ and enjoy reputation benefits at $t=2$ according to the firm's performance ${ }^{30}$. His interim participation constraint is written as:

$$
\begin{gathered}
p^{i}\left(\bar{e}_{2}\left(w^{i, h}+f\left(q^{i, h}\right)\right)+\left(1-\bar{e}_{2}\right)\left(w^{i, l}+f\left(q^{i, l}\right)\right)\right)+\left(1-p^{i}\right)\left(w^{i, l}+f\left(q^{i, l}\right)\right)-c \geq \\
p^{i}\left(\bar{e}_{2} f\left(q^{i, h}\right)+\left(1-\bar{e}_{2}\right) f\left(q^{i, l}\right)\right)+\left(1-p^{i}\right) f\left(q^{i, l}\right),
\end{gathered}
$$

which simplifies to:

$$
p^{i}\left(\bar{e}_{2} w^{i, h}+\left(1-\bar{e}_{2}\right) w^{i, l}\right)+\left(1-p^{i}\right) w^{i, l} \geq c .
$$

Condition (17) simply states that the expected monetary wage must cover the effort cost.

Last, we impose limited liability on the manager's side: all wages must be non negative.

\footnotetext{
${ }^{29}$ Alternatively, shareholders could decide to continue operating the firm without providing incentives for effort exertion. In that case, they simply give a second period wage equal to zero.

${ }^{30}$ Technically, the interim participation constraint of a newly hired manager should also be written. It is obvious however that the latter will always accept to be hired since he has no reputation concerns: his expected wage will always exceed his cost of effort.
} 
Suppose first that $R_{h}$ occurred in period one. If the manager in place at $t=0$ is retained, we have: $f\left(q^{h, h}\right)-f\left(q^{h, l}\right)=0$, and $p^{h}=1$. Constraint (15) becomes:

$$
w^{h, h}-w^{h, l} \geq \frac{c}{\Delta e_{2}} .
$$

As is standard in moral hazard problems, to maximize the shareholders' payoffs, the optimal contract is: $w^{h, h}=\frac{c}{\Delta e_{2}}$ and $w^{h, l}=0$. Note that in that case, condition (16) is the same, and the same contract will be given to a new manager if the firm decides to fire the initial manager. We will see however that this is not optimal for first period incentives.

Given the optimal contract, condition (17) is automatically satisfied : since the incumbent manager's reputation is the same regardless of the second period performance, he can only be incentivized with monetary incentives, and the second-period wage more than covers the effort cost (he earns a positive agency rent).

Suppose next that $R_{l}$ occurred in period one. If the initial manager is retained, condition (15) is:

$$
w^{l, h}-w^{l, l} \geq \frac{c}{p^{l} \Delta e_{2}}-\left(f\left(q^{l, h}\right)-f\left(q^{l, l}\right)\right) .
$$

And condition (17):

$$
p^{l}\left(\bar{e}_{2} w^{l, h}+\left(1-\bar{e}_{2}\right) w^{l, l}\right)+\left(1-p^{l}\right) w^{l, l} \geq c .
$$

To maximize the shareholders' profits, one chooses the minimum wages that satisfy (15) and (17). Clearly, $w^{l, l}=0$ is optimal (although the optimal wage contract is not unique when (15) is slack). If constraint (15) is binding, the optimal contract is:

$$
\begin{aligned}
& w^{l, h}=\max \left[0 ; \frac{c}{p^{l} \Delta e_{2}}-\Delta f\right], \\
& \text { and } \\
& w^{l, l}=0 .
\end{aligned}
$$

It is easy to see that this contract satisfies the manager's participation constraint iff:

$$
w^{l, h} \geq \frac{c}{p^{l} \bar{e}_{2}} .
$$

If the above condition is violated, the optimal contract sets $w^{l, h}$ and $w^{l, l}$ such that constraint (17) is binding, and constraint (15) is fulfilled. Overall, the optimal contract is ${ }^{31}$ :

$$
\begin{aligned}
& w^{l, h}=\max \left[\frac{c}{p^{l} \bar{e}_{2}} ; \frac{c}{p^{l} \Delta e_{2}}-\Delta f\right], \\
& \text { and } \\
& w^{l, l}=0 .
\end{aligned}
$$

If the initial manager is fired, condition (16) leads to:

$$
\begin{aligned}
& w^{l, h}=\frac{c}{p^{l} \Delta e_{2}}, \\
& \text { and } \\
& w^{l, l}=0 .
\end{aligned}
$$

\footnotetext{
${ }^{31}$ Note that in the case where condition (15) is not binding, the optimal contract is not unique. Nevertheless, it will always imply $w^{l, h}>w^{l, l}$ since condition (15) must be satisfied.
} 


\section{Determination of Assumption 1}

Shareholders must be willing to continue operating the firm, and to induce effort at $t=1$, given the wage contracts determined in Proposition 1. Since operating the firm without inducing effort generates strictly positive profits, their interim participation constraint is:

$$
\begin{gathered}
p^{i}\left(\bar{e}_{2}\left(R^{h}-w^{i, h}\right)+\left(1-\bar{e}_{2}\right)\left(R^{l}-w^{i, l}\right)\right)+\left(1-p^{i}\right)\left(R^{l}-w^{i, l}\right) \geq \\
p^{i}\left(\underline{e}_{2}\left(R^{h}-w^{i, h}\right)+\left(1-\underline{e}_{2}\right)\left(R^{l}-w^{i, l}\right)\right)+\left(1-p^{i}\right)\left(R^{l}-w^{i, l}\right) .
\end{gathered}
$$

Suppose that $R^{h}$ occurs at $t=1$. Condition (18) is written:

$$
\Delta e_{2}\left(R^{h}-R^{l}\right) \geq \frac{\bar{e}_{2} c}{\Delta e_{2}} .
$$

Suppose next that $R^{l}$ occurs. Condition (18) depends on whether shareholders retain the original manager or hire a new one. Note that a newly hired manager is always granted a higher second period wage: this is simply because he has no reputation concern to incentivize him. Using the value of $w_{\text {new }}^{l, h}$ in (18), a sufficient condition for shareholders to continue operating the firm and induce effort when $R^{l}$ occurs is:

$$
\Delta e_{2}\left(R^{h}-R^{l}\right) \geq \frac{\bar{e}_{2} c}{p^{l} \Delta e_{2}}
$$

which is exactly condition (9) in assumption 1. A simple comparison with condition (19) shows that condition (9) is sufficient to ensure that shareholders are willing to continue and induce effort for any first period cash flow $^{32}$.

\section{Proof of Lemma 1}

Having determined the optimal second period wages, we now turn to the determination of first period wages for the incumbent manager. The optimal wage contract simply minimizes the expected wage payment subject to the following constraints.

First, the incentive compatibility condition of the incumbent manager, given the optimal second period contract determined in Proposition 1 is written as:

$$
\begin{gathered}
q_{0}\left[\bar{e}_{1}\left(w^{h}+V^{h}\right)+\left(1-\bar{e}_{1}\right)\left(w^{l}+V^{l, G}\right)\right]+\left(1-q_{0}\right) V^{l, B}-c \geq \\
q_{0}\left[\underline{e}_{1}\left(w^{h}+V^{h}\right)+\left(1-\underline{e}_{1}\right)\left(w^{l}+V^{l, G}\right)\right]+\left(1-q_{0}\right) V^{l, B},
\end{gathered}
$$

where:

$$
\begin{aligned}
V^{h} & =\bar{e}_{2} w^{h, h}+f(1)-c, \\
V^{l, G} & =\bar{e}_{2}\left(w^{l, h}+f(1)\right)+\left(1-\bar{e}_{2}\right) f\left(q^{l, l}\right)-c, \\
V^{l, B} & =f\left(q^{l, l}\right)-c .
\end{aligned}
$$

\footnotetext{
${ }^{32}$ If condition (9) does not hold, we have different regimes: one in which shareholders induce the original manager, but not a newly hired one, to exert effort after $R^{l}$, another regime where they prefer not to induce effort after $R^{l}$, but to induce effort after $R^{h}$ and possibly a regime in which they do not want to induce second period effort at all. Considering these different regimes will not bring much insight to the analysis.
} 
Condition (20) implicitly assumes that the manager who is retained chooses effort $\bar{e}_{2}$ in the second period, even if he exerts effort $\underline{e}_{1}$ at $t=1$. It is easy to see that this is always true given the second period optimal wage contract: indeed, we always have $p^{i}\left(\bar{e}_{1}\right) \leq p^{i}\left(\underline{e}_{1}\right)$. Since second period wages are set given $p^{i}\left(\bar{e}_{1}\right)$, the initial manager will be even more willing to exert effort $\bar{e}_{2}$, if he chose $\underline{e}_{1}$.

Clearly, $w^{l}$ has a negative impact on first period incentives: it is optimal to set $w^{l}=0$. Also, retaining the manager after good performance boosts his incentives to exert effort: it is therefore optimal ex ante to promise to retain the manager in case of good performance. Replacing second period wages by their value and rearranging terms leads straightforwardly to the following condition:

$$
w^{h} \geq \frac{c}{q_{0} \Delta e_{1}}-\bar{e}_{2}\left(w^{h, h}-w^{l, h}\right)-\left(1-\bar{e}_{2}\right) \Delta f .
$$

Last, imposing that wages must be nonnegative completes the proof of Lemma 1.

\section{Proof of Proposition 3}

Suppose that shareholders can commit to a long-term contract specifying whether the manager is fired or not in case of bad interim performance, i.e. if $R^{l}$ occurs in period one. To the extent that committing to retaining the manager is not an issue (since it is the ex post optimal policy for shareholders) the net benefit of committing to an employment policy is simply measured by the difference between the firm's ex ante value when the manager is fired after $R^{l}$, and when he is retained. To compare the two, one must compute the incumbent manager's first period wage, if he is dismissed in case of bad performance. Denote this wage by $\hat{w}^{i}$.

Proceeding as in the proof of Lemma 1, the first period incentive compatibility condition under the threat of dismissal is given by constraint (20), where continuation payoffs are:

$$
\begin{aligned}
V^{h} & =\bar{e}_{2} w^{h, h}+f(1)-c, \\
V^{l, G} & =\bar{e}_{2} f(1)+\left(1-\bar{e}_{2}\right) f\left(q^{l, l}\right), \\
V^{l, B} & =f\left(q^{l, l}\right) .
\end{aligned}
$$

Again, it is optimal to set $\hat{w}^{l}=0$. Replacing second-period wages and continuation payoffs by their value, and rearranging terms, condition (20) states that:

$$
\hat{w}^{h} \geq \frac{c}{q_{0} \Delta e_{1}}-\left(\bar{e}_{2} w^{h, h}-c\right)-\left(1-\bar{e}_{2}\right) \Delta f .
$$

Since wages cannot be negative, the optimal first period wage under the threat of dismissal is simply:

$$
\hat{w}^{h}=\max \left[0, \frac{c}{q_{0} \Delta e_{1}}-\left(\bar{e}_{2} w^{h, h}-c\right)-\left(1-\bar{e}_{2}\right) \Delta f\right] .
$$


Straight comparison with the first period wage without the threat of dismissal $w^{h}$ (defined in Lemma 1) shows that $w^{h} \geq \hat{w}^{h}$. The entrenched manager must be given a higher first period wage to be induced to exert effort because he will be retained even in case of bad performance.

The net benefit of committing to an employment policy is thus equal to:

$$
\begin{gathered}
q_{0}\left[\bar{e}_{1}\left(R^{h}-\hat{w}^{h}+\bar{e}_{2}\left(R^{h}-w^{h, h}\right)+\left(1-\bar{e}_{2}\right) R^{l}\right)+\left(1-\bar{e}_{1}\right)\left(R^{l}+\bar{e}_{2}\left(R^{h}-w_{\text {new }}^{l, h}\right)+\left(1-\bar{e}_{2}\right) R^{l}\right)\right] \\
+\left(1-q_{0}\right) 2 R^{l} \\
-q_{0}\left[\bar{e}_{1}\left(R^{h}-w^{h}+\bar{e}_{2}\left(R^{h}-w^{h, h}\right)+\left(1-\bar{e}_{2}\right) R^{l}\right)+\left(1-\bar{e}_{1}\right)\left(R^{l}+\bar{e}_{2}\left(R^{h}-w_{\text {old }}^{l, h}\right)+\left(1-\bar{e}_{2}\right) R^{l}\right)\right] \\
-\left(1-q_{0}\right) 2 R^{l},
\end{gathered}
$$

Commitment is only valuable if the above expression is positive. Simplifying it yields (10).

When deriving expression (10), we implicitly assumed that shareholders always want to induce effort at $t=0$. Without agency problems, this is always true (see condition (1)). With agency problems, the condition is slightly modified because wages now include a rent to incentivize managers. It is written:

$$
\Delta e_{1}\left(R^{h}-R^{l}-w^{h}-e_{2} w^{h, h}\right)+\left(1-\underline{e}_{1}\right) \bar{e}_{2} w_{\underline{e}_{1}}^{l, h}-\left(1-\bar{e}_{1}\right) \bar{e}_{2} w_{\bar{e}_{1}}^{l, h} \geq 0 .
$$

Note that increasing $R^{h}-R^{l}$ always relaxes the above condition, while not conflicting assumptions 1 and 2, which ensures the consistency of the model.

\section{Proof of Corollary 2}

Corollary 2 is easily obtained by replacing wages $w^{h}, w^{h, h}, \hat{w}^{h}, w_{\text {new }}^{l, h}$ by their value in expression (10) under assumption 2 (that ensures that all wages are strictly positive). The net gain of committing to an employment policy is then expressed by:

$$
q_{0} \max \left[\bar{e}_{2} w_{\text {old }}^{l, h}-\bar{e}_{1} c-\left(1-\bar{e}_{1}\right) \bar{e}_{2} \frac{c}{p^{l} \Delta e_{2}} ; 0\right] .
$$

Remember that $w_{\text {old }}^{l, h}$ can take two values, depending on whether the participation or the incentive compatibility constraint of the incumbent manager is binding. When the participation constraint is binding, $w_{\text {old }}^{l, h}=\frac{c}{p^{l} \bar{e}_{2}}$, and expression (22) is written as in (12). When the incentive compatibility constraint is binding, $w_{\text {old }}^{l, h}=\frac{c}{p^{l} \Delta e_{2}}-\Delta f$, and expression (22) is written as in (13).

\section{Proof of Proposition 4}

If a new manager is hired, his (IC) constraint is the same as before, except that the probability of working on a good strategy is given by $1-p^{l}$ after the strategy change. Therefore,

$$
w_{\text {switch }, \text { new }}^{l, h}=\frac{c}{\left(1-p^{l}\right) \Delta e_{2}}, w_{\text {switch }, \text { new }}^{l, l}=0 .
$$

If the incumbent manager continues to be employed under a new strategy his incentive compatibility con- 
straint can be written as:

$$
\begin{aligned}
& \left(1-p^{l}\right)\left(\bar{e}_{2}\left(w_{\text {switch,old }}^{l, h}+f(0)\right)+\left(1-\bar{e}_{2}\right)\left(w_{\text {switch,old }}^{l, l}+f\left(q_{c}^{l, l}\right)\right)\right) \\
& +p^{l}\left(w_{\text {switch old }}^{l, l}+f\left(q_{c}^{l, l}\right)\right)-c \\
& \geq\left(1-p^{l}\right)\left(\underline{e}_{2}\left(w_{\text {switch,old }}^{l, h}+f(0)\right)+\left(1-\underline{e}_{2}\right)\left(w_{\text {switch }, \text { old }}^{l, l}+f\left(q_{c}^{l, l}\right)\right)\right) \\
& +p^{l}\left(w_{\text {switch,old }}^{l, l}+f\left(q_{c}^{l, l}\right)\right),
\end{aligned}
$$

where $q_{\text {switch }}^{l, l}$ is the manager's reputation if the firm performs poorly twice and the strategy is changed at the interim date. As usual it is optimal to set $w_{\text {switch,old }}^{l, l}=0$ and therefore the (IC) constraint can be re-written as:

$$
w_{\text {switch }, \text { old }}^{l, h} \geq \frac{c}{\left(1-p^{l}\right) \Delta e_{2}}-\left(f(0)-f\left(q_{c}^{l, l}\right)\right) .
$$

Since $f(0)<f\left(q_{\text {switch }}^{l, l}\right)$ for a manager with reputational concerns, it follows immediately that the incentive payment to the incumbent manager must be higher than that to a new manager. Since the wage to the old manager must be high enough to satisfy his incentive compatibility constraint (but may be higher if the participation constraint is harder to satisfy), it follows that it is always cheaper to employ a new manager.

\section{Proof of Lemma 2}

It is clear that the manager's (IC) constraint is unchanged when the strategy remains the same. It is still expressed by constraint (15) page 27 .

The participation constraint might be altered because the reservation utility of the original manager depends on the firm's strategic choice if he resigns. In particular, the firm can decide to hire a new manager and continue the old strategy, or change for the alternative strategy. Clearly, the original manager's reputation will not evolve the same way according to this choice. We need to consider when the firm will prefer to change strategy if the original manager resigns.

Given that a new manager is hired, the firm shareholders will opt for the new strategy if and only if:

$$
\begin{aligned}
p^{l}\left[\bar{e}_{2}\left(R^{h}-w_{\text {stick,new }}^{l, h}\right)+\left(1-\bar{e}_{2}\right) R^{l}\right]+\left(1-p^{l}\right) R^{l} \leq \\
\left(1-p^{l}\right)\left[\bar{e}_{2}\left(R^{h}-w_{\text {switch,new }}^{l, h}\right)+\left(1-\bar{e}_{2}\right) R^{l}\right]+p^{l} R^{l} .
\end{aligned}
$$

It follows immediately that shareholders will change strategy if and only if: $p^{l} \geq \frac{1}{2}$ (the expected wage payment is the same in both cases, and shareholders choose the strategy with the highest probability of success).

It follows that:

(i) if $p^{l}<\frac{1}{2}$ and the manager resigns, the firm chooses to change strategy, and the manager's participation constraint is now given by:

$$
\begin{array}{r}
p^{l}\left(\bar{e}_{2}\left(w_{\text {stick,old }}^{l, h}+f\left(q^{l, h}\right)\right)+\left(1-\bar{e}_{2}\right)\left(w_{\text {stick }, \text { old }}^{l, l}+f\left(q^{l, l}\right)\right)\right)+\left(1-p^{l}\right)\left(w_{\text {stick }, \text { old }}^{l, l}+f\left(q^{l, l}\right)\right)-c \geq \\
\left(1-p^{l}\right)\left(\bar{e}_{2} f(0)+\left(1-\bar{e}_{2}\right) f\left(q_{\text {switch }}^{l, l}\right)\right)+p^{l} f\left(q_{\text {switch }}^{l, l}\right) .
\end{array}
$$

Noting that $w_{\text {stick,old }}^{l, l}=0$, this can be rearranged to:

$$
w_{\text {stick,old }}^{l, h} \geq \frac{c}{p^{l} \bar{e}_{2}}+K,
$$


where:

$$
K=\frac{f\left(q_{s w i t c h}^{l, l}\right)-f\left(q^{l, l}\right)}{p^{l} \bar{e}_{2}}-\Delta f-\frac{1-p^{l}}{p^{l}}\left(f\left(q_{s w i t c h}^{l, l}\right)-f(0)\right) .
$$

(ii) If $p^{l} \geq \frac{1}{2}$ and the manager resigns, the firm chooses to continue with the old strategy, and the manager's participation constraint is unchanged. The wage contracts are therefore given by (6).

\section{Proof of Proposition 5}

If the firm wants to continue the original strategy, it has the choice between retaining the original manager and giving him a wage $w_{\text {stick,old }}^{l, h}$ and hiring a new manager with a wage $w_{\text {stick,new }}^{l, h}{ }^{33}$

Under the optimal renegotiation-proof contract, it will choose the cheaper solution, and retain the original manager if and only if:

$$
w_{\text {stick,old }}^{l, h} \leq w_{\text {stick, new }}^{l, h},
$$

If $p^{l} \geq \frac{1}{2}$, condition (26) is always true (from Proposition 2 and Lemma 2). If $p^{l}<\frac{1}{2}$, (26) is equivalent to:

$$
\max \left[\frac{c}{p^{l} \Delta e_{2}}-\Delta f ; \frac{c}{p^{l} \bar{e}_{2}}+K\right] \leq \frac{c}{p^{l} \Delta e_{2}},
$$

which is always true if :

$$
\frac{c}{p^{l} \bar{e}_{2}}+K \leq \frac{c}{p^{l} \Delta e_{2}}
$$

Rearranging terms yields condition (14).

\section{Proof of Proposition 6}

Shareholders will stick to the initial strategy if and only if:

$$
\begin{aligned}
p^{l}\left(\bar{e}_{2}\left(R_{h}-w_{\text {stick }}^{l, h}\right)+\right. & \left.\left(1-\bar{e}_{2}\right) R_{l}\right)+\left(1-p^{l}\right) R_{l} \geq \\
& \left(1-p^{l}\right)\left(\bar{e}_{2}\left(R_{h}-w_{\text {switch }, \text { new }}^{l, h}\right)+\left(1-\bar{e}_{2}\right) R_{l}\right)+p^{l} R_{l},
\end{aligned}
$$

The above inequality can be rearranged as:

$$
p^{l} \geq \frac{1}{2}-\frac{\left(1-p^{l}\right) w_{\text {switch,new }}^{l, h}-p^{l} w_{\text {stick }}^{l, h}}{2\left(R^{h}-R^{l}\right)} \equiv p^{*}
$$

\section{Proof of Corollary 3}

\footnotetext{
${ }^{33}$ Recall that $w_{\text {stick }}^{l, l}=0$.
} 
To establish corollary 3 , one simply needs to replace the different wages by their value. If the firm switches strategy, the wage payment is given by equation (23) page 31:

$$
w_{\text {switch,new }}^{l, h}=\frac{c}{\left(1-p^{l}\right) \Delta e_{2}} \text {. }
$$

If the firm continues under the old strategy, it will do so under the incumbent or the new manager as stated in Proposition 5. Hence:

$$
w_{\text {stick }}^{l, h}=\min \left\{w_{\text {stick,new }}^{l, h}, w_{\text {stick }, \text { old }}^{l, h}\right\} .
$$

where the incumbent manager second period wage $w_{\text {stick,old }}^{l, h}$ is given in lemma 2 , and $w_{\text {stick,new }}^{l, h}=\frac{c}{p^{l} \Delta e_{2}}$.

If condition 14 holds, replacing $w_{\text {stick, old }}$ by its value, it follows straightforwardly that $\left(1-p^{l}\right) w_{\text {switch,new }}^{l, h}$ $p^{l} w_{\text {stick,old }}^{l, h}>0$ and $p^{*}<\frac{1}{2}$.

If condition 14 does not hold, we have:

$$
w_{\text {stick }}^{l, h}=w_{\text {stick,old }}^{l, h}=\frac{c}{p^{l} \Delta e_{2}},
$$

and $p^{*}=\frac{1}{2}$. 


\section{REFERENCES}

[1] Abowd, John, and David Kaplan, 1999, "Executive Compensation: six Questions that need Answering," Journal of Economic Perspectives, 13(4), 145-168.

[2] Acharya, Viral, Kose John and Rangarajan Sundaram, 2000, "On the Optimality of Resetting Executive Stock Options," Journal of Financial Economics, 57, 65-101.

[3] Aghion, Philippe, and Patrick Bolton, 1992, "An Incomplete Contract Approach to Financial Contracting," Review of Economic Studies, 59, 473-494.

[4] Almazan, Andres, and Javier Suarez, 2003, "Entrenchment and Severance Pay in Optimal Governance Structures," Journal of Finance, 58(2), 519-548.

[5] Bebchuk, Lucian, and Jesse Fried, 2003, "Executive Compensation as an Agency Problem," Journal of Economic Perspectives, 17(3), 71-92.

[6] Berkovitch, Elazar, Ronen Israel, and Yossef Spiegel, 2000, "Managerial Compensation and Capital Structure," Journal of Economics and Management Strategy, 9, 549-584.

[7] Bertrand, Marianne, and Sendhil Mullainathan, 1999, "Is there a Discretion in Wage Setting? A Test using Takeover Legislation," RAND Journal of Economics, 30(3), 535-554.

[8] Bertrand, Marianne, and Sendhil Mullainathan, 2001, "Are CEOs Rewarded for Luck? The Ones Without Principals are," Quarterly Journal of Economics, 116(3), 901-932.

[9] Bizjak, John, James Brickley, and Jeffrey Coles, 1993, "Stock Based Incentive Compensation and Investment Behavior," Journal of Accounting and Economics, 16, 349-372.

[10] Bolton, Patrick, and David Scharfstein, 1990, "A Theory of Predation based on Agency Problems in Financial Contracting," American Economic Review, 80, 93-106.

[11] Boot, Arnoud, 1992, "Why Hang on to Losers? Divestitures and Takeovers," Journal of Finance, 47, 1401-1423.

[12] Brenner, Menachem, Rangarajam Sundaran, and David Yermack, 2000, "Altering the Terms of Executive Stock Options," Journal of Financial Economics, 57, 103-128.

[13] Carter, Mary Ellen, and Luann Lynch, 2001, "An Examination of Executive Stock Option Repricing," Journal of Financial Economics, 61, 207-225.

[14] Chance, Don, Raman Kumar, and Rebecca Todd, 2000, "The 'Repricing' of Executive Stock Options," Journal of Financial Economics, 57, 129-154.

[15] Chen, Mark, 2004, "Executive Option Repricing, Incentives and Retention," Journal of Finance, 59(3), 1167-1199.

[16] Chidambaran, Nenmara, and Nagpurnanand Prabhala, 2003, "Executive Stock Option repricing, International Governance Mechanisms, and Management Turnover," Journal of Financial Economics, 69, 153-189. 
[17] Crémer, Jacques, 1995, "Arm's Length Relationships " Quarterly Journal of Economics, 110 (2), 275-295.

[18] Dass, N., 2006, "Why are Firms Value or Growth?" unpublished manuscript, INSEAD.

[19] Denis, David, and Diane Denis, 1995, "Performance Changes Following Top Management Dismissals," Journal of Finance, 50, 1029-1057.

[20] Dewatripont, Mathias, Ian Jewitt, and Jean Tirole, 1999, "The Economics of Career Concerns, Part I: Comparing Information Structure " Review of Economic Studies, 66, 183-201.

[21] Dewatripont, Mathias, and Eric Maskin, 1995, "Credit and Efficiency in Centralized and Decentralized Economies, "Review of Economic Studies, 62, 541-555.

[22] Dewatripont, Mathias, and Jean Tirole, 1994, "A Theory of Debt and Equity: Diversity of Securities and Manager-Shareholder Congruence," Quarterly Journal of Economics, 139, 10271054 .

[23] Diamond, Douglas, 1984, "Financial Intermediation and Delegated Monitoring, " Review of Economic Studies, 51, 393-414.

[24] Dow, James, and Clara Raposo, 2005, "CEO Compensation, Change and Corporate Strategy," Journal of Finance, 60, 2701-2727.

[25] Eisfeldt, Andrea, and Adriano Rampini, 2004, "Letting Go: Managerial Incentives and the Reallocation of Capital," unpublished manuscript, Northwestern University.

[26] Eisfeldt, Andrea, and Adriano Rampini, 2005, "Capital Reallocation and Liquidity," unpublished manuscript, Northwestern University.

[27] Fee, Edward, and Charles Hadlock, 2003, "Raids, Rewards and Reputations in the Market for Managerial Talent," Review of Financial Studies, 16, 1315-1357.

[28] Fluck, Zsuzsanna, 1998, "Optimal Financial Contracting: Debt Versus Outside Equity," Review of Financial Studies, 11, 383-418.

[29] Franks, Julian, and Colin Mayer, 1996, "Hostile Takeovers in the UK and the Correction of Managerial Failure," Journal of Financial Economics, 40, 163-181.

[30] Friebel, Guido, and Michael Raith, 2004, "Abuse of Authority and Hierarchical Communication, " RAND Journal of Economics, 35, 224-244.

[31] Gale, Douglas, and Martin Hellwig, 1985, "Incentive-Compatible Debt Contracts: The OnePeriod Problem, " Review of Economic Studies, 52, 647-663.

[32] Gibbons, Robert, and Kevin J. Murphy, 1992, "Optimal Incentive Contracts in the Presence of Career Concerns: Theory and Evidence," Journal of Political Economy, 100, 468-505.

[33] Gordon, Shelley, Wayne Stewart, Robert Sweo, and William Luker, 2000, "Convergence versus Strategic Reorientation: the Antecedents of Fast-paced Organizational Change," Journal of Management, 26, 911-945. 
[34] Gorton, Gary, and Bruce Grundy, 1997, "Executive Compensation and the Optimality of Managerial Entrenchment," unpublished manuscript, Wharton School.

[35] Holmstrom, Bengt, 1979, "Moral Hazard and Observability," Bell Journal of Economics 10, 74-91.

[36] Holmstrom, Bengt, 1982, "Managerial Incentive Problems: A Dynamic Perspective, " in Essays in Economics and Management in Honor of Lars Wahlbeck (Helsinki: Swedish School of Economics).

[37] Holmstrom, Bengt, and Joan Ricart i Costa, 1986, "Managerial Incentives and Capital Management," Quarterly Journal of Economics, 101, 835-860.

[38] Jeon, Seonghoon, 1998 "Reputational Concerns and Managerial Incentives in Investment Decisions," European Economic Review, 42, 1203-1219.

[39] Joos, Philip, Andrew Leone, and Jerold Zimmermann, 2002, "Selecting CEOs: Matching the Person to the Job," unpublished manuscript Rochester University.

[40] Lant, Theresa, and Frances Milliken, 1992, "The Role of Managerial Learning and Interpretation in Strategic Persistence and Reorientation: an Empirical Exploration, " Strategic Management Journal, 13, 585-608.

[41] Milbourn, Todd, Richard Shockley, and Anjan Thakor, 2001, "Managerial Career Concerns and Investments in Information," RAND Journal of Economics, 32, 334-351.

[42] Murphy, Kevin, 1999, "Executive Compensation, " Handbook of Labor Economics, Vol. 3b, Chapter 38, 2485-2563, Orley Ashenfelter and David Card (eds.), Elsevier Science North Holland.

[43] Murphy, Kevin, 2002, "Explaining Executive Compensation: Managerial Power versus the Perceived Cosat of Stock Options," University of Chicago Law Review, 69, 847-869.

[44] Ortega, Jaime, 2003, "Power in the Firm and Managerial Career Concerns, " Journal of Economics and Management Strategy, 12, 1-29.

[45] Oyer, Paul, 2004, "Why Do Firms Use Incentives that have no Incentive Effects?" Journal of Finance , 59, 1619-1649.

[46] Prendergast, Canice, 1999, "The Provision of Incentives in Firms" Journal of Economic Literature , 37, 7-63.

[47] Prendergast, Canice and Lars Stole, 1996, "Impetuous Youngsters and Jaded Old-Timers: Acquiring a Reputation for Learning," Journal of Political Economy, 104, 1105-1134.

[48] Pourciau, Susan, 1993, "Earnings Management and Non-routine Executive Changes," Journal of Accounting and Economics, 16, 317-336.

[49] Rogerson, William, 1985, "Repeated Moral-Hazard," Econometrica, 53, 69-76.

[50] Romanelli, Elaine, and Michael Tushman, 1994, "Organizational Transformation as Punctuated Equilibrium, " Academy of Management Journal, 37, 1141-1166. 
[51] Shleifer, Andrei, and Robert Vishny, 1989, "Managerial Entrenchment: The Case of ManagerSpecific Investments," Journal of Financial Economics, 25, 123-139.

[52] Shleifer, Andrei, and Robert Vishny, 1990, "Equilibrium Short Horizons of Investors and Firms," American Economic Review Papers and Proceedings, 80, 148-153.

[53] Spear, Stephen, and Cheng Wang, 2005, "When to Fire a CEO: Optimal Termination in Dynamic Contracts," Journal of Economic Theory, 120(2), 239-256.

[54] Stein, Jeremy, 1988, "Takeover Threats and Managerial Myopia," Journal of Political Economy, 96, 61-80.

[55] Stein, Jeremy, 1989, "Efficient Capital Markets, Inefficient Firms: A Model of Myopic Corporate Behavior," Quarterly Journal of Economics, 104, 655-669.

[56] v. Thadden, Ernst-Ludwig, 1995, "Long-Term Contracts, Short-Term Investment and Monitoring," Review of Economic Studies, 62, 557-575.

[57] Zwiebel, Jeffrey, 1996, "Managerial Entrenchment under Dynamic Capital Structure," American Economic Review, 86, 1197-1215. 